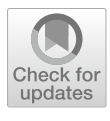

Cite as

Nano-Micro Lett.

(2021) 13:104

Received: 1 January 2021

Accepted: 22 February 2021

Published online: 5 April 2021

(C) The Author(s) 2021

\title{
A Natural Polymer Captor for Immobilizing Polysulfide/Polyselenide in Working $\mathrm{Li}_{-} \mathrm{SeS}_{2}$ Batteries
}

Yin Zhang ${ }^{1}$, Menglei Wang ${ }^{2}$, Yi Guo ${ }^{1}$, Lingzhi Huang ${ }^{1}$, Boya Wang ${ }^{1}$, Yunhong Wei ${ }^{1}$, Peng Jing ${ }^{1}$, Yueying Zhang ${ }^{1}$, Yun Zhang ${ }^{1}$, Qian Wang ${ }^{1}$, Jingyu Sun ${ }^{2}$, Hao Wu ${ }^{1 凶}$

\section{HIGHLIGHTS}

- Theoretical calculations reveal that Nicandra physaloides pectin can serve as Lewis base to realize strong interaction toward both lithium polysulfide and polyselenides.

- Nicandra physaloides pectin is introduced into a conductive double-carbon self-supporting film to build an anchoring and regulating interlayer for $\mathrm{Li}_{-} \mathrm{SeS}_{2}$ batteries.

- The $\mathrm{Li}-\mathrm{SeS}_{2}$ pouch cells assembled with the interlayers deliver good flexibility and stability to demonstrate a viable strategy for developing working $\mathrm{Li}_{-} \mathrm{SeS}_{2}$ batteries.

ABSTRACT $\mathrm{SeS}_{2}$ has become a promising cathode material owing to its enhanced electrical conductivity over sulfur and higher theoretical specific capacity than selenium; however, the working $\mathrm{Li}-\mathrm{SeS}_{2}$ batteries have to face the practical challenges from the severe shuttling of soluble dual intermediates of polysulfide and polyselenide, especially in high-SeS $\mathrm{S}_{2}$-loading cathodes. Herein, a natural organic polymer, Nicandra physaloides pectin (NPP), is proposed to serve as an effective polysulfide/polyselenide captor to address the shuttling issues. Informed by theoretical calculations, NPP is competent to provide a Lewis base-based strong binding interaction with polysulfides/polysele-

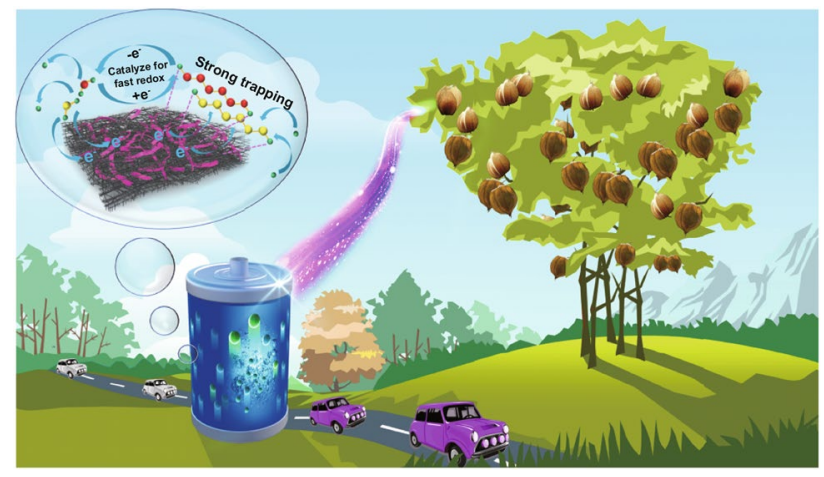
nides via forming lithium bonds, and it can be homogeneously depos-

ited onto a three-dimensional double-carbon conductive scaffold to finally constitute a polysulfide/polyselenide-immobilizing interlayer. Operando spectroscopy analysis validates the enhanced polysulfide/polyselenide trapping and high conversion efficiency on the constructed interlayer, hence bestowing the $\mathrm{Li}-\mathrm{SeS}_{2}$ cells with ultrahigh rate capability $\left(448 \mathrm{mAh} \mathrm{g}^{-1}\right.$ at $\left.10 \mathrm{~A} \mathrm{~g}^{-1}\right)$, durable cycling lifespan $(\approx 0.037 \%$ capacity attenuation rate per cycle), and high areal capacity $\left(>6.5 \mathrm{mAh} \mathrm{cm}^{-2}\right)$ at high $\mathrm{SeS}_{2}$ loading of $15.4 \mathrm{mg} \mathrm{cm}^{-2}$. Importantly, pouch cells assembled with this interlayer exhibit excellent flexibility, decent rate capability with relatively low electrolyte-to-capacity ratio, and stable cycling life even under a low electrolyte condition, promising a low-cost, viable design protocol toward practical Li-SeS ${ }_{2}$ batteries.

KEYWORDS Li-SeS 2 batteries; Nicandra physaloides pectin; Interlayer; Shuttle effect; Pouch cells

$\triangle$ Yun Zhang, y_zhang@scu.edu.cn; Jingyu Sun, sunjy86@suda.edu.cn; Hao Wu, hao.wu@ scu.edu.cn

1 Engineering Research Center of Alternative Energy Materials and Devices of Ministry of Education, College of Materials Science and Engineering, Sichuan University, Chengdu 610064, People's Republic of China

2 Key Laboratory of Advanced Carbon Materials and Wearable Energy Technologies of Jiangsu Province, College of Energy, Soochow Institute for Energy and Materials Innovations (SIEMIS), Soochow University, Suzhou 215006, People's Republic of China 


\section{Introduction}

The fast growth of compact electronic devices and electric vehicles pushes researchers to focus on the exploitation of high energy density storage systems. Because of the high theoretical specific capacity $\left(1675 \mathrm{mAh} \mathrm{g}^{-1}\right)$ and energy density (2600 $\mathrm{Wh} \mathrm{kg}^{-1}$ ), lithium-sulfur ( $\mathrm{Li}-\mathrm{S}$ ) batteries have grabbed ever-increasing attention [1]. Nevertheless, the poor conductivity of sulfur, the shuttling of dissolved lithium polysulfides $\left(\mathrm{Li}_{2} \mathrm{~S}_{\mathrm{n}}, 4 \leq n \leq 8\right)$, and volume expansion during discharge-charge process seriously hinder their practical applications [2]. Given this, lithium-selenium ( $\mathrm{Li}-\mathrm{Se}$ ) batteries come into researchers' view due to the higher conductivity of selenium $\left(1 \times 10^{-3} \mathrm{~S} \mathrm{~m}^{-1}\right)$ than sulfur $\left(5 \times 10^{-28}\right.$ $\mathrm{S} \mathrm{m}^{-1}$ ) and equivalent volume specific capacity (3254 mAh $\mathrm{cm}^{-3}$ ) compared to Li-S batteries (3467 $\mathrm{mAh} \mathrm{cm}^{-3}$ ) [3] Nonetheless, the high industrial cost and low mass specific capacity $\left(675 \mathrm{mAh} \mathrm{g}^{-1}\right)$ of element selenium undermine its appeal as the electrode materials $[4,5]$.

To combine the advantages of S and Se, the solid solution selenium sulfide $\left(\mathrm{SeS}_{2}\right)$ has become a promising cathode material [6]. Thanks to the higher specific capacity (1345 $\mathrm{mAh} \mathrm{g}^{-1}$ ) than Se and the enhanced conductivity compared with $\mathrm{S}$, the $\mathrm{SeS}_{2}$-based cathode materials have drawn great attention [7, 8]. In Amine's pioneer work, $\mathrm{SeS}_{2}$, as a cathode material, exhibits tremendous potential for $\mathrm{Li}$ and $\mathrm{Na}$ storage [6]. Since then, the mechanism of electrochemical reaction and the cause of capacity degradation in ether-based electrolyte have been further researched. As the cathode material of Li metal batteries, $\mathrm{SeS}_{2}$ displays analogical electrochemical reaction to $\mathrm{S}$ and $\mathrm{Se}$, meaning that $\mathrm{SeS}_{2}$ as the cathode also easily suffers the common shuttling problem of soluble dual intermediates of lithium polysulfides and lithium polyselenides $\left(\mathrm{Li}_{2} \mathrm{~S}_{\mathrm{n}}\right.$ and $\left.\mathrm{Li}_{2} \mathrm{Se}_{\mathrm{n}}, 4 \leq \mathrm{n} \leq 8\right)$, which results in the irreparable loss of active species, fast capacity decay, and terrible self-discharge $[9,10]$. Vast attempts have been implemented to inhibit the shuttling of soluble $\mathrm{Li}_{2} \mathrm{~S}_{\mathrm{n}} / \mathrm{Li}_{2} \mathrm{Se}_{\mathrm{n}}$ and extend the lifespan of $\mathrm{Li}-\mathrm{SeS}_{2}$ batteries. To date, carbon materials (e.g., mesoporous carbon [11], double-layered hollow carbon sphere [12, 13], and CMK3 [14]) and polar materials (e.g., metal nitrides [15-17] and metal sulfides [18, 19]) have been applied in fabricating $\mathrm{SeS}_{2}$ cathodes in order to physically or chemically capture active species. Dismayingly, most of these porous carbon materials only render limited absorption to dissolved $\mathrm{Li}_{2} \mathrm{~S}_{\mathrm{n}} / \mathrm{Li}_{2} \mathrm{Se}_{\mathrm{n}}$, meanwhile the electrochemically inert carbon generally decreases the final $\mathrm{SeS}_{2}$ areal loading $\left(<2.0 \mathrm{mg} \mathrm{cm}^{-2}\right)$ and actual $\mathrm{SeS}_{2}$ content $(<60 \mathrm{wt} \%)$ of electrode. Besides, both the complicated process and the high cost of the porous carbon materials still result in a long distance from the commercial application standards.

Recently, an increasing interest has focused on the novel adsorbents with merits of wide raw material sources, low price, and easy construction. Some organics with hydroxyl groups and amine groups have showed strong affinity with $\mathrm{Li}_{2} \mathrm{~S}_{\mathrm{n}}$ in $\mathrm{Li}-\mathrm{S}$ batteries, so as to decrease the loss of active materials and meliorate the cycling performance [20]. For example, Dong and his co-workers have demonstrated that a polypropylene separator modified by tertiary amine layer can selectively bond with the soluble long-chain $\mathrm{Li}_{2} \mathrm{~S}_{\mathrm{n}}$ based on the classic "soft and hard acid-base (SHAB) theory" [21]. In addition, some natural organics, such as $\beta$-cyclodextrin polymer [22], lignin fibers [23], Gum Arabic [24], and proteins $[25,26]$, are combined with conductive materials to retard the dissolution and shuttling of $\mathrm{Li}_{2} \mathrm{~S}_{\mathrm{n}}$ for enhancing the electrochemical performance of $\mathrm{Li}-\mathrm{S}$ batteries. Nevertheless, for all we know, there is no report referring to exploring natural organics to be simultaneously served as $\mathrm{Li}_{2} \mathrm{~S}_{\mathrm{n}}$ and $\mathrm{Li}_{2} \mathrm{Se}_{\mathrm{n}}$ adsorbents in $\mathrm{Li}-\mathrm{SeS}_{2}$ batteries, and the resulting effects to immobilizing these soluble intermediates and regulating their electrochemical performance are unknown. Moreover, very few attempts have been made so far on the fabrication of high-performance working $\mathrm{Li}-\mathrm{SeS}_{2}$ batteries under realistic conditions, such as pouch cells with high $\mathrm{SeS}_{2}$ loading and lean electrolyte, yet which is a prerequisite for realizing the commercialization of $\mathrm{Li}-\mathrm{SeS}_{2}$ batteries.

Herein, guided by density functional theory (DFT) calculations, we report that an effective natural organic polymer of Nicandra physaloides pectin (denoted as NPP) is competent to realize strong chemical interaction and immobilization toward both $\mathrm{Li}_{2} \mathrm{~S}_{\mathrm{n}}$ and $\mathrm{Li}_{2} \mathrm{Se}_{\mathrm{n}}$, as it can ideally serve on the Lewis base to provide electrons and generate strong lithium bonds with the soluble dual intermediates. By introducing the NPP, assembled as a ribbon-like network, into a three-dimensional (3D) double-carbon conductive skeleton consisted of cotton carbon fibers (CF) and carbon nanotubes (CNTs), a freestanding hybrid film (CF@CNTs-NPP) is successfully constructed via a simple solution deposition method. The as-built CF@ CNTs-NPP hybrid film with a 3D open structure not only favors the electrolyte infiltration without detaining too much electrolyte, but also functions as upper current collectors to 
ensure rapid ionic/electronic transport and good compatibility with high-areal-loading $\mathrm{SeS}_{2}$ cathodes. Operando analysis by in situ Raman spectroscopy further demonstrates the enhancement of trapping ability and conversion efficiency of $\mathrm{Li}_{2} \mathrm{~S}_{\mathrm{n}}$ l $\mathrm{Li}_{2} \mathrm{Se}_{\mathrm{n}}$ on the CF@CNTs-NPP film. With this designed interlayer, we greatly enhance the electrochemical performances of a easily made $\mathrm{SeS}_{2} / \mathrm{CNTs}$ cathode (70 $\mathrm{wt} \% \mathrm{SeS}_{2}$ content), as reflected by a considerably restrained self-discharge behavior, an outstanding cyclability with a capacity retention as high as $98.9 \%$ over 250 cycles at $1 \mathrm{~A} \mathrm{~g}^{-1}$ and $70 \%$ over 800 cycles at 2 $\mathrm{A} \mathrm{g}^{-1}$, as well as an superhigh rate capability of $448 \mathrm{mAh} \mathrm{g}^{-1}$ at $10 \mathrm{~A} \mathrm{~g}^{-1}$, being the highest rate performance ever reported for $\mathrm{Li}-\mathrm{SeS}_{2}$ batteries. Even at a largely increased $\mathrm{SeS}_{2}$ areal loading of $15.4 \mathrm{mg} \mathrm{cm}^{-2}$, it also achieves a high areal capacity over $6.6 \mathrm{mAh} \mathrm{cm} \mathrm{cm}^{-2}$, which surpasses the traditional lithium-ion batteries. More significantly, the designed CF@ CNTs-NPP interlayer gives rise to superior performances in a $\mathrm{Li}-\mathrm{SeS}_{2}$ pouch cell configuration in terms of favorable flexibility, high discharge capacity $\left(751 \mathrm{mAh} \mathrm{g}^{-1}\right)$, low electrolyteto-capacity ratio $\left(\approx 7.8 \mu \mathrm{L}(\mathrm{mA} \mathrm{h})^{-1}\right)$, high $\mathrm{SeS}_{2}$ utilization efficiency ( $>55 \%)$, and stable cycling life $(\approx 90.1 \%$ capacity retention over 70 cycles) even under high $\mathrm{SeS}_{2}$ loading and low electrolyte operation.

\section{Experimental Section}

\subsection{Preparation of NPP}

$100 \mathrm{~g}$ commercial Nicandra physaloides (L.) Gaertn seeds were added into $1000 \mathrm{~mL}$ deionized water and kept stirring for an hour. Then, the mixture was filtered with gauze to obtain light yellow viscous filtrate. After the filtrate was frozen, the Nicandra physaloides pectin (NPP) were obtained by vacuum freeze-drying.

\subsection{Preparation of CF@CNTs-NPP, CF@CNTs, and CF Interlayers}

The household cotton tissues (CT) composed by natural cotton were washing by deionized water and absolute alcohol, followed by dried at $60{ }^{\circ} \mathrm{C}$ for $12 \mathrm{~h}$. Next, the carbon nanotubes (CNTs) dispersion with a content of $10 \mathrm{wt} \%$ purchased from Chengdu Organic Chemicals Co., LTD. Chinese Academy of Sciences was diluted with $100 \mathrm{~mL}$ deionized water to get a slurry of CNTs with a concentration of about
$2 \mathrm{mg} \mathrm{mL}^{-1}$ after an ultrasonic treatment for $1 \mathrm{~h}$. Then, the dried CT were immersed into the dispersion of CNTs with ultrasonic treatment for $30 \mathrm{~min}$, followed by dried at $100{ }^{\circ} \mathrm{C}$ for $12 \mathrm{~h}$. After that, the CT adsorbed CNTs were carbonized at $900{ }^{\circ} \mathrm{C}$ for $2 \mathrm{~h}$ with the Ar atmosphere to obtain CF@ CNTs. The as-obtained films were cut into pieces with a diameter of $15 \mathrm{~mm}$ as the CF@CNTs interlayers. The NPP was dissolved into the mixture of deionized water and absolute alcohol $(\mathrm{v} / \mathrm{v}=4: 1)$ with a content of $4 \mathrm{mg} \mathrm{mL}^{-1}$. Then, $60 \mu \mathrm{L}$ NPP solution was dropped onto each CF@CNTs interlayer, followed by immersion in liquid nitrogen. After completely frozen, the solids were freeze-dried for $36 \mathrm{~h}$ and then dried at $60^{\circ} \mathrm{C}$ for $12 \mathrm{~h}$ in a vacuum oven to obtain $\mathrm{CF} @$ CNTs-NPP interlayers. In addition, the CF@CNTs-NPP interlayers with the size of $2.5 \times 4.5 \mathrm{~cm}^{2}$ for pouch cells are obtained through the same process except for adding $382 \mu \mathrm{L}$ NPP solution. Besides, the CF interlayers were got by the direct carbonization of CT.

\subsection{Material Characterization}

Field-emission scanning electron microscopy (FESEM) images were collected on Hitachi S-4800 instrument, which is equipped with energy-dispersive X-ray (EDX) system for elemental mapping. X-ray diffraction (XRD) measurement was taken on a Bruker DX-1000 diffractometer using $\mathrm{Cu} \mathrm{K} \alpha$ radiation. The chemical element composition on the surface of composites was identified by X-ray photoelectron spectroscopy (XPS, AXIS Ultra DLD, Kratos) analysis. Fourier transform infrared (FT-IR) spectrum was performed on the Nicolet-5700 in the range of $400-4000 \mathrm{~cm}^{-1}$. Thermogravimetric analysis (TGA) was recorded on a simultaneous TGA/DSC-2 instrument (METTLER TOLEDO, USA). Raman spectra were collected on a Raman spectrophotometer (HORIBA Jobin Yvon, HR800, France) with $532 \mathrm{~nm}$ laser radiation. The UV-Vis data were collected by Shimadzu UV 3600. The square resistances were measured at room temperature using a ST2258A digital four point probe test system (Suzhou Jingge Electronic Co., Ltd).

\subsection{Electrochemical Measurements}

The selenium disulfides/carbon nanotubes $\left(\mathrm{SeS}_{2} / \mathrm{CNTs}\right)$ composite was prepared by mixing the commercial CNTs 
powder and $\mathrm{SeS}_{2}$ with a ratio of 70:30 by grinding, and the precursor was sealed in a reactor and heated at $160{ }^{\circ} \mathrm{C}$ for $10 \mathrm{~h}$. The $\mathrm{SeS}_{2} / \mathrm{CNTs}$ composite $(90 \mathrm{wt} \%)$ was mixed with sodium carboxymethyl cellulose (CMC, $5 \mathrm{wt} \%)$ and styrene butadiene rubber (SBR, $5 \mathrm{wt} \%$ ) in deionized water solvent to form a slurry and cast onto carbon-coated aluminum foils. After dried in a vacuum oven at $50{ }^{\circ} \mathrm{C}$ for $24 \mathrm{~h}$, the electrodes were cut into circular pieces with a diameter of $12 \mathrm{~mm}$ with the areal $\mathrm{SeS}_{2}$ loading about $1.3 \mathrm{mg} \mathrm{cm}^{-2}$. Besides, the slurry was coated onto carbon paper for higher $\mathrm{SeS}_{2}$ loadings from 4.5 to $15.4 \mathrm{mg} \mathrm{cm}^{-2}$. The coin cells (CR2032) were assembled in an argon-filled glove box for electrochemical tests using Li foil as anodes, Celgard 2400 as separators and $\mathrm{Li}-\mathrm{SeS}_{2}$ electrolyte of $1 \mathrm{M}$ lithium bis(trifluoromethanesulfonyl)-imide (LiTFSI) in 1,3-dioxolane (DOL) and 1,2-dimethoxyethane (DME) with volume ratio $1: 1$ and $2 \mathrm{wt} . \% \mathrm{LiNO}_{3}$ as additive. The interlayers were placed between $\mathrm{SeS}_{2} / \mathrm{CNTs}$ cathodes and separators. For the soft-packed Li-SeS $\mathrm{S}_{2}$ batteries, the $\mathrm{SeS}_{2} / \mathrm{CNTs}$ cathodes were cut into $2 \times 4 \mathrm{~cm}^{2}$ pieces. Galvanostatic charge/ discharge tests were performed using a multichannel battery test system (Neware CT-3008 W, China) within the potential range $1.7-2.8 \mathrm{~V}\left(v s . \mathrm{Li} / \mathrm{Li}^{+}\right)$at different current densities. Cyclic voltammetry (CV) measurements were taken using a PARSTAT multichannel electrochemical workstation (Princeton Applied Research, USA). Electrochemical impedance spectroscopy (EIS) was conducted over a frequency range of $100 \mathrm{kHz}$ to $0.1 \mathrm{~Hz}$ with an applied amplitude of $5 \mathrm{mV}$.

\section{Results and Discussion}

NPP, one of the most abundant and renewable biomass in nature, mainly comes from the natural Nicandra physaloides (L.) Gaertn, an annual herb of the Solanaceae family, which is native to Peru and widely distributed in Yunnan, Sichuan, Guizhou, and some other places in China [27, 28]. There is a layer of non-toxic, colorless, tasteless, edible colloids outside the seeds of the $N$. physaloides, and these colloids (i.e., NPP) can be readily isolated by simple water extraction with great yields [28]. As shown in Fig. 1a, NPP is composed largely of a backbone of a $\alpha-1,4$-linked galacturonic acid, many of which are esterified with methyl alcohol at the carboxylic acid, interspersed with a few rhamnose, galactose, and glucose residues linked to neutral side chains [29, 30].
To identify the chemical structure of NPP molecules, X-ray photoelectron spectroscopy (XPS) and Fourier transform infrared (FT-IR) spectrum were conducted. As shown in Fig. S1a, the XPS survey spectrum shows two strong binding energy peaks related to the $\mathrm{C} 1 \mathrm{~s}$ and $\mathrm{O} 1 \mathrm{~s}$, respectively. The C $1 \mathrm{~s}$ spectrum of NPP (Fig. S1b) presents the existence of the carboxylate $\mathrm{C}(\mathrm{HO}-\mathrm{C}=\mathrm{O})$, ester $\mathrm{C}(\mathrm{O}-\mathrm{C}=\mathrm{O})$, hydroxyl $\mathrm{C}(\mathrm{C}-\mathrm{OH})$, and non-oxygenated ring $\mathrm{C}(\mathrm{C}-\mathrm{C} /$ $\mathrm{C}=\mathrm{C}$ ) $[31,32]$. Simultaneously, the O $1 \mathrm{~s}$ spectrum of NPP can be divide into two peaks, associated with the $\mathrm{C}=\mathrm{O}$ and $\mathrm{C}-\mathrm{O}-\mathrm{H} / \mathrm{C}-\mathrm{O}-\mathrm{C}$ bonds, respectively (Fig. S1c) [26, 33]. As for the FT-IR spectra of NPP (Fig. S2), the distinct peaks at 3419 and $2934 \mathrm{~cm}^{-1}$ belong to the stretching vibration of $\mathrm{O}-\mathrm{H}$ and $\mathrm{C}-\mathrm{H}$ bonds, respectively [34]. The peaks at 1728 and $1608 \mathrm{~cm}^{-1}$ are present due to the stretching vibrations of $\mathrm{C}=\mathrm{O}$ bonds in ester and carboxyl, respectively $[29,35]$. The peak at $1420 \mathrm{~cm}^{-1}$ are existing for the symmetric vibrations of $\mathrm{O}-\mathrm{C}-\mathrm{O}$ bonds, while the peak at $1238 \mathrm{~cm}^{-1}$ is attributed to the $\mathrm{C}-\mathrm{O}-\mathrm{H}$ deformation of pyranose rings [36]. The peaks located between 1200 and $1000 \mathrm{~cm}^{-1}$ correspond to the bending vibration of $\mathrm{C}-\mathrm{O}-\mathrm{C}$ glycosidic bonds in polysaccharide [37, 38]. Note that the weak absorption peaks in the low frequency region of $900-800 \mathrm{~cm}^{-1}$ are probably related to $\alpha$-glycosidic bonds, which implies the existence of $\alpha$-glycosidic bonds in NPP [34]. These results demonstrate that the NPP certainly is abundant in oxygen-containing groups, which could afford a powerful adsorption toward $\mathrm{Li}_{2} \mathrm{~S}_{\mathrm{n}} / \mathrm{Li}_{2} \mathrm{Se}_{\mathrm{n}}$ and thus retard the shuttle effect.

To investigate the chemical interactions between the NPP and the $\mathrm{Li}_{2} \mathrm{~S}_{\mathrm{n}} / \mathrm{Li}_{2} \mathrm{Se}_{\mathrm{n}}$, DFT calculations were firstly conducted by adopting $\mathrm{Li}_{2} \mathrm{~S}_{6}$ and $\mathrm{Li}_{2} \mathrm{Se}_{6}$ as the models. The interaction between the key components of NPP (galactose, glucose, galacturonic acid, and rhamnose) and the $\mathrm{Li}_{2} \mathrm{~S}_{6}$ / $\mathrm{Li}_{2} \mathrm{Se}_{6}$ are displayed in Fig. 1b, c. As shown in Fig. 1b, because $\mathrm{Li}_{2} \mathrm{~S}_{\mathrm{n}}$ molecules have "electron cloud holes" to accept electrons from other molecules, the electron-rich functional groups in NPP, such as hydroxyl, ester, and epoxy groups, can provide electrons and form strong lithium bonds with $\mathrm{Li}_{2} \mathrm{~S}_{\mathrm{n}}$ according to the Lewis base-based chemical bonding, which is consist with the concept proposed by Zhang et al. [24, 39, 40]. Meanwhile, owing to the similar chemical property between $\mathrm{Li}_{2} \mathrm{~S}_{\mathrm{n}}$ and $\mathrm{Li}_{2} \mathrm{Se}_{\mathrm{n}}$, the similar lithium bonds with $\mathrm{Li}_{2} \mathrm{Se}_{\mathrm{n}}$ also exist toward NPP (Fig. 1c). Differential charge density analyses are displayed in Fig. $\mathrm{S} 3$, in which the increased electron densities between the lithium in $\mathrm{Li}_{2} \mathrm{~S}_{\mathrm{n}} / \mathrm{Li}_{2} \mathrm{Se}_{\mathrm{n}}$ and the oxygen in NPP ascertain the 
(a)

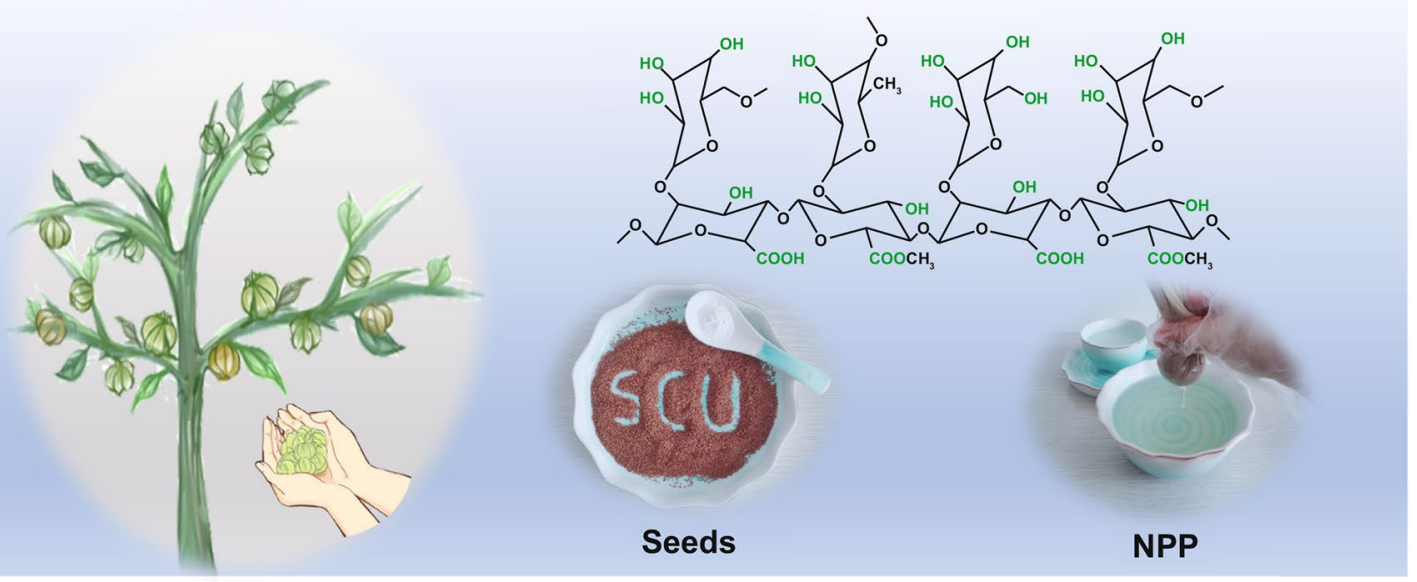

(b)

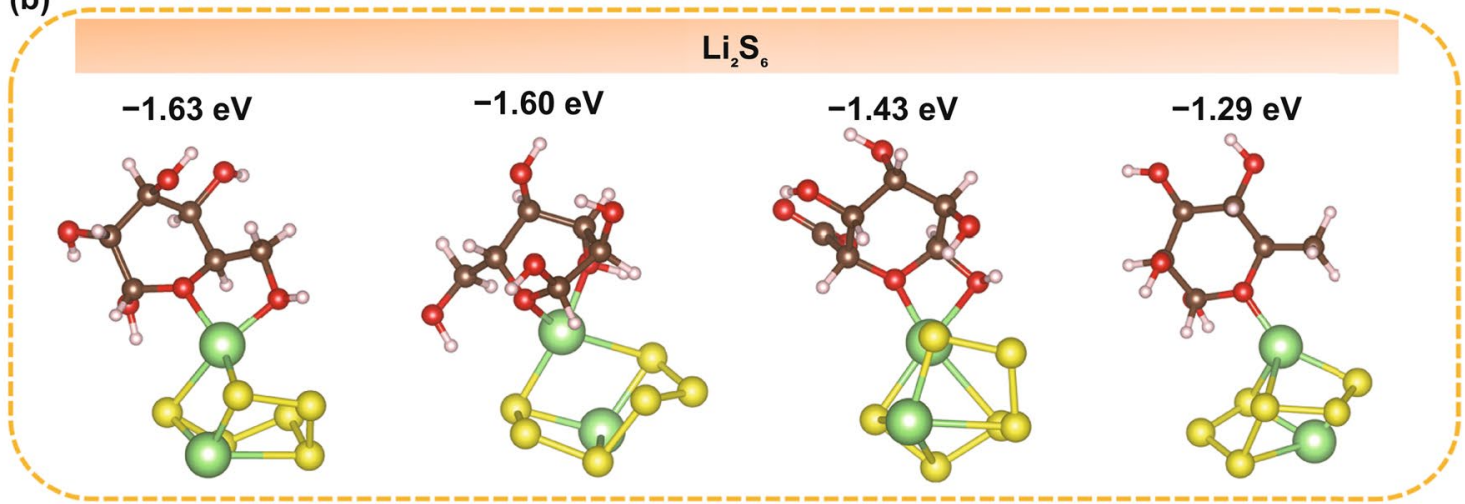

(c)

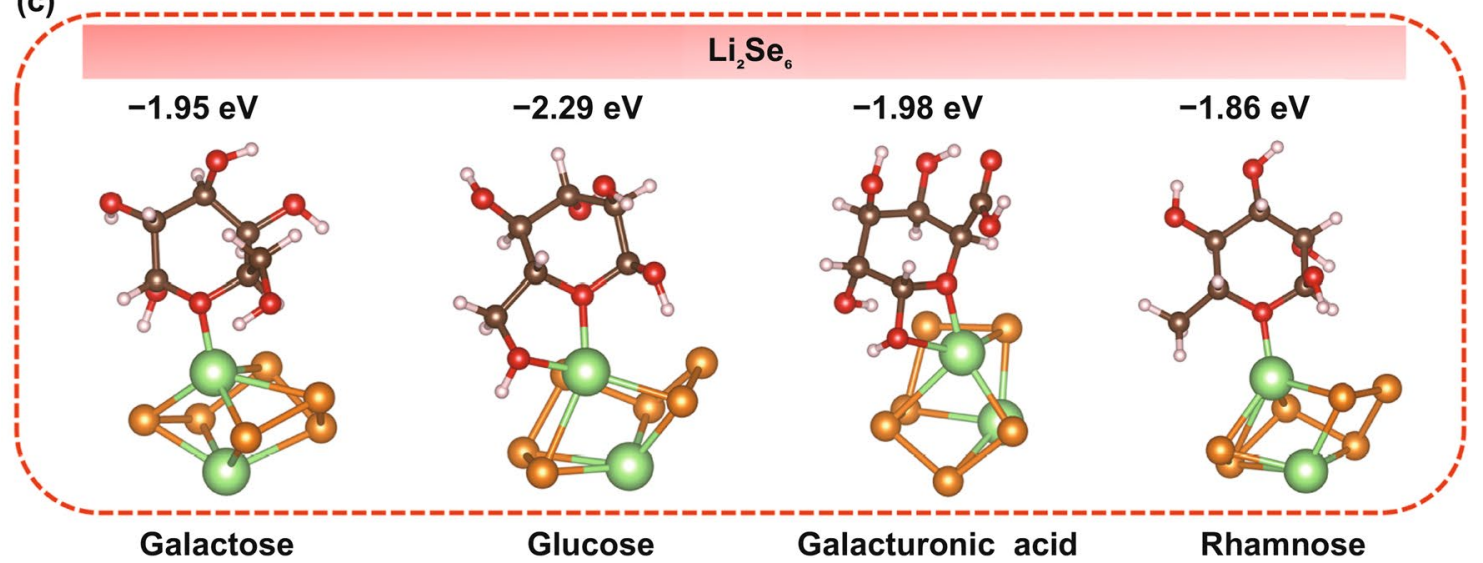

Fig. 1 a Schematic diagram of the extraction process of the NPP. The optimized structures of four typical main components of NPP adsorbed

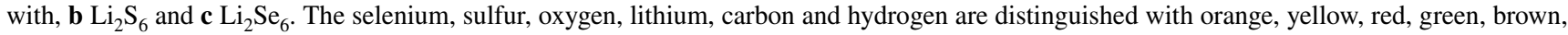
and white. (Color figure online)

formation of lithium bonds. Accordingly, the results of calculated adsorption energy are also represented in Fig. 1b, c. The constitutional units of NPP, such as galactose, glucose, galacturonic acid, and rhamnose, can afford the binding energies of $-1.63,-1.60,-1.43$, and $-1.29 \mathrm{eV}$ with $\mathrm{Li}_{2} \mathrm{~S}_{6}$, respectively. Surprisingly, one can see that there are higher binding energies of $-1.95,-2.29,-1.98$, and $-1.86 \mathrm{eV}$ between galactose, glucose, galacturonic acid, and rhamnose with $\mathrm{Li}_{2} \mathrm{Se}_{6}$, respectively, as compared with $\mathrm{Li}_{2} \mathrm{~S}_{6}$. Informed by these DFT results, it is predicted that the NPP 
not only possesses strong chemisorption to trap $\mathrm{Li}_{2} \mathrm{~S}_{\mathrm{n}}$, but also exhibits superior trapping and confinement to $\mathrm{Li}_{2} \mathrm{Se}_{\mathrm{n}}$, implying that NPP can be used in $\mathrm{Li}_{-}-\mathrm{SeS}_{2}$ batteries to retard the shuttling of $\mathrm{Li}_{2} \mathrm{~S}_{\mathrm{n}} / \mathrm{Li}_{2} \mathrm{Se}_{\mathrm{n}}$.

Compared with complex architecture design of cathode materials, engineering functional interlayers is a cost-effective and easily producible strategy. As shown in Fig. 2a, the NPP was coated on the double-carbon CF@CNTs conductive frameworks to obtain CF@CNTs-NPP hybrid. The detailed preparation processes are depicted in the experimental section. The inexpensive household cotton tissues (denoted as CT, the insert of Fig. 2b), as the 3D carbon network precursor were immersed into and absorbed the suspension solution of CNTs. As revealed in Fig. 2b, e, the

(a)
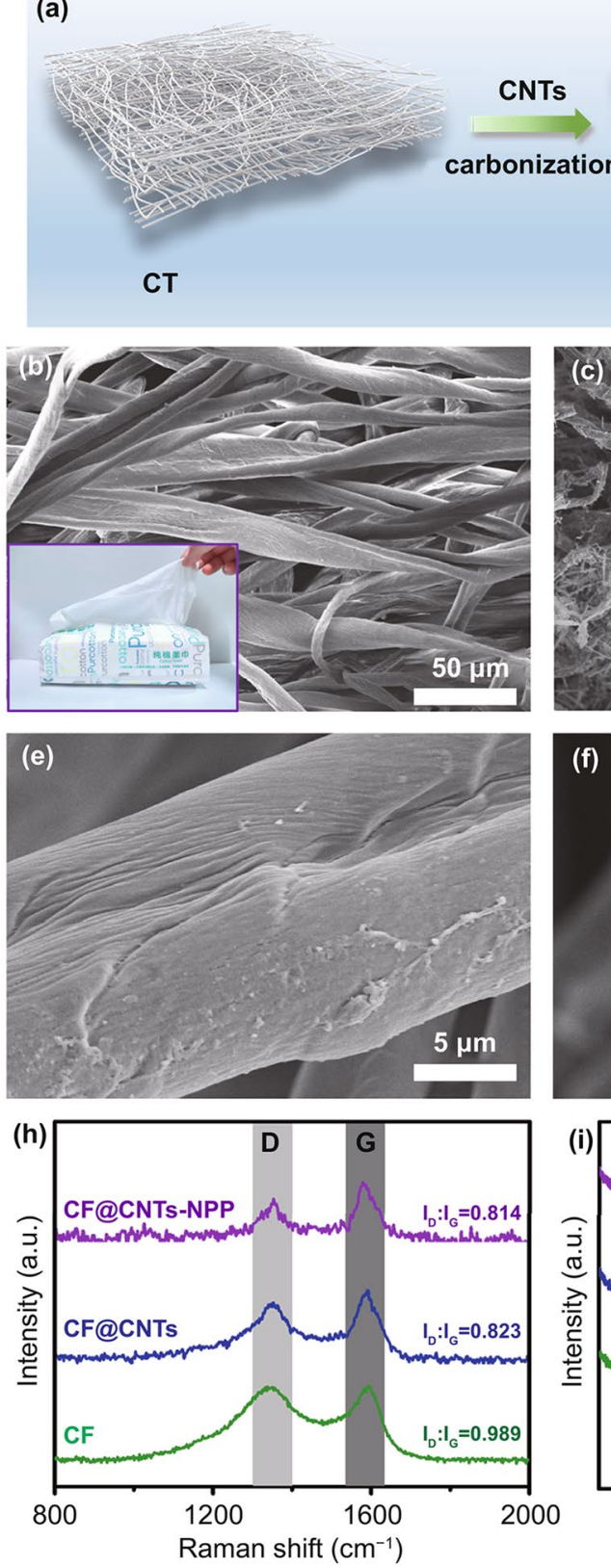
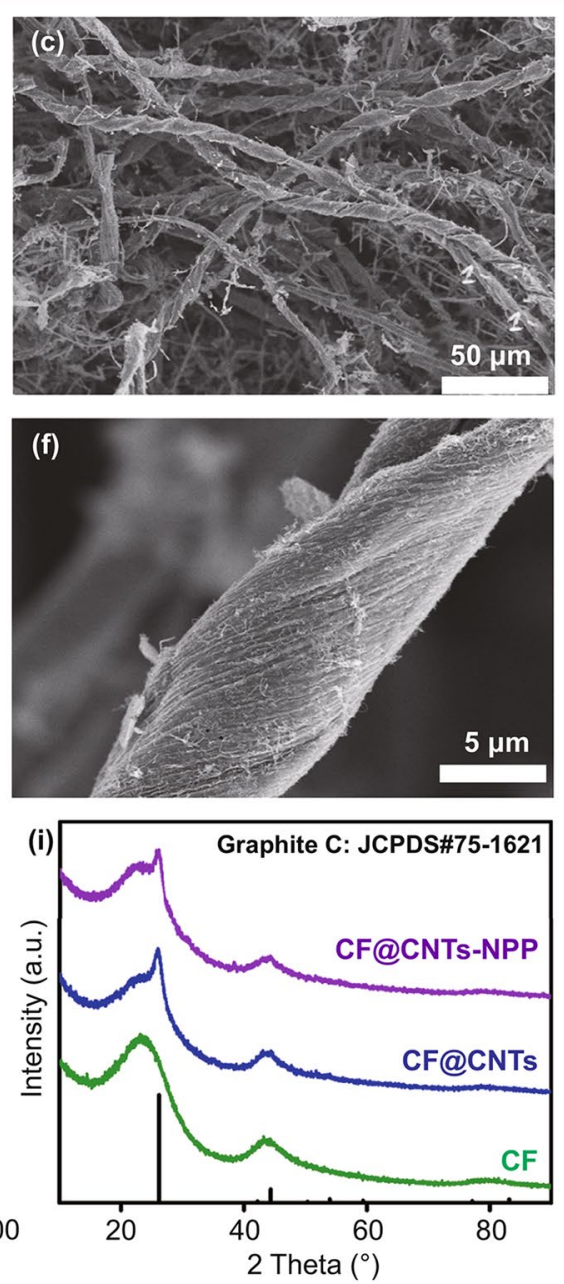
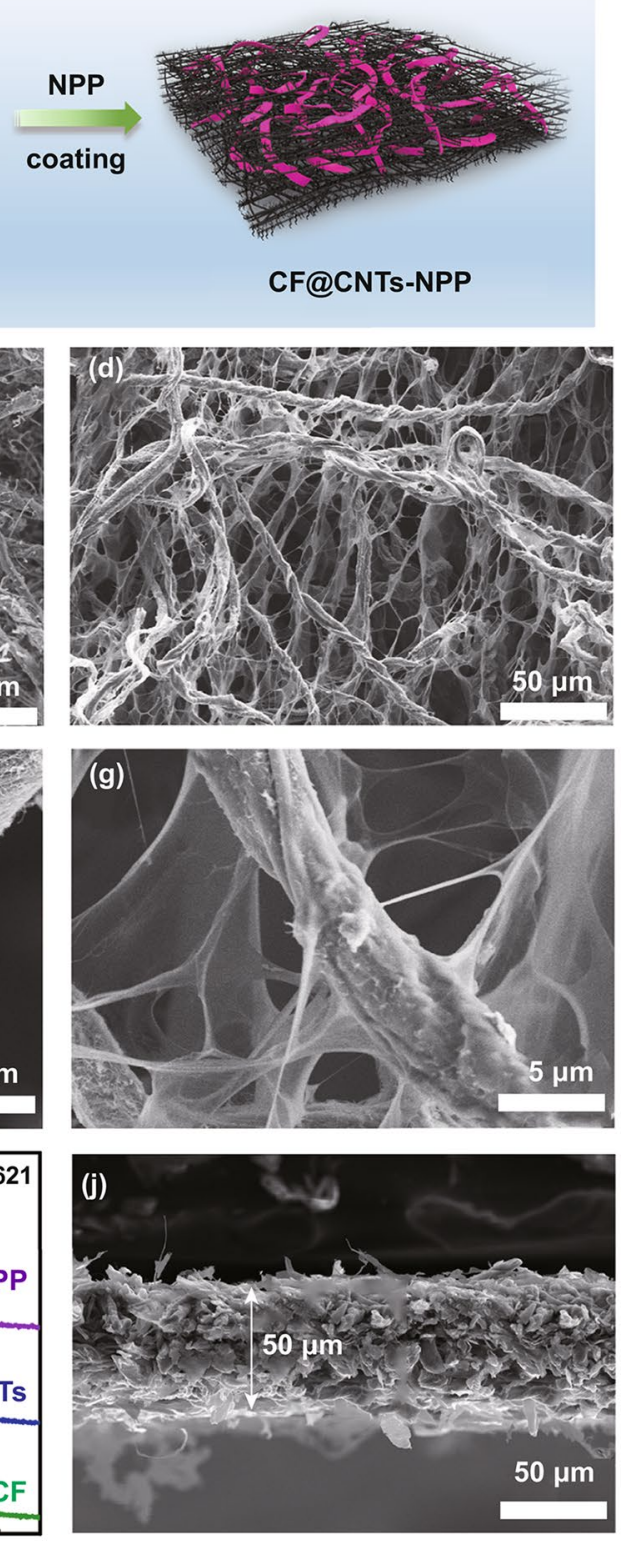

Fig. 2 a Schematic diagram of the fabrication process of the CF@CNTs-NPP composite. Top-view FESEM images of b, e CF, c, f CF@CNTs, and d, g CF@CNTs-NPP composite. h Raman spectra and i XRD patterns of CF, CF@CNTs, and CF@CNTs-NPP. j Cross-sectional FESEM image of the CF@CNTs-NPP interlayer 
CT network possesses ample interspace constructed by cotton fibers with a diameter of $\approx 20 \mu \mathrm{m}$. Benefiting from the strong wettability of natural cotton [41], the CT can absorb the CNTs suspended in the aqueous solution to form CT@ CNTs composite, as observed in their optical images in Fig. S4a, b. After that, the dried CT@CNTs composite was carbonized at $900{ }^{\circ} \mathrm{C}$ in an $\mathrm{Ar}$ atmosphere, in which the cotton fibers converted to $\mathrm{CF}$ with a shrinking size, as exhibited in Fig. S4c. From the further observation of field-emission scanning electron microscopy (FESEM) images in Fig. 2c, $\mathrm{f}$, the intertwined CNTs not only cover the CF uniformly, but also fill in the interspace between $\mathrm{CF}$, which constructs the self-supporting 3D double-carbon conductive CF@CNTs scaffold. By contrast, the CF obtained from direct carbonization of CT possesses 3D network constructed by carbon nanofibers with a smooth surface (Fig. S5). Since the introduction of CNTs, the as-built CF@CNTs has a higher graphitization degree than the bare $\mathrm{CF}$, which can be testified by Raman spectroscopy. As depicted in Fig. 2h, the CF@CNTs displays a lower peak intensity ratio of $I_{\mathrm{D}} / I_{\mathrm{G}}(0.823)$ than that of bare $\mathrm{CF}$ (0.989) [42]. Moreover, the X-ray diffraction (XRD) pattern of CF@CNTs appears a sharp characteristic peak of graphitized carbon at $26.2^{\circ}$ (Fig. 2i), while the bare CF only displays a broad peak of amorphous carbon around $26^{\circ}$. All these results indicate the more enhanced electrical conductivity of the CF@CNTs over the bare CF, which is further testified by square resistance tests, as exhibited in Table S1. Besides, as shown in Fig. S6, the CF and CF@ CNTs both exhibit excellent flexibility and foldability.

Subsequently, the as-built CF@CNTs conductive framework was coated by the NPP through dropwise adding the NPP-containing dispersion solution so as to form the CF@ CNTs-NPP hybrid. As shown in Fig. 2d, g, the NPP assembled as a ribbon-like network not only wrap the surface of CF@CNTs skeleton, but also is interconnected to form a 3D CF@CNTs-NPP network with enhanced flexibility. Note that the introduction of insulating organics NPP has almost no significant effect on reducing the conductivity of the CF@CNTs-NPP, which can be verified by the Raman spectroscopy (Fig. 2h) and the XRD patterns (Fig. 2i). Specifically, the CF@CNTs-NPP exhibits an approximate peak intensity ratio of $I_{\mathrm{D}} / I_{\mathrm{G}}(0.814)$ compared with CF@CNTs $(0.823)$ and remains the characteristic XRD peak at $26.2^{\circ}$ associated with the graphitized carbon. In addition, the CF@ CNTs-NPP hybrid film maintains glorious flexibility and foldability with a diameter length of $15 \mathrm{~mm}$ (Fig. S7), while the thickness of CF@CNTs-NPP hybrid film was estimated to be $\approx 50 \mu \mathrm{m}$ in the cross-sectional FESEM image (Fig. 2j).

To verify the adsorption ability of the CF@CNTs-NPP hybrid, visualized $\mathrm{Li}_{2} \mathrm{~S}_{\mathrm{n}}$ and $\mathrm{Li}_{2} \mathrm{Se}_{\mathrm{n}}$ adsorption experiments were carried out. As shown in Fig. 3a, the same amounts of CF, CF@CNTs, and CF@CNTs-NPP were added into the as-prepared $\mathrm{Li}_{2} \mathrm{~S}_{\mathrm{n}}$ and $\mathrm{Li}_{2} \mathrm{Se}_{\mathrm{n}}$ solutions, respectively. After kept still for $12 \mathrm{~h}$, all the solutions containing adsorbing materials become lighter than the bare one, especially for the $\mathrm{Li}_{2} \mathrm{Se}_{\mathrm{n}}$ solution contacted with the CF@CNTs-NPP. Compared with the $\mathrm{Li}_{2} \mathrm{~S}_{\mathrm{n}}$ solution containing CF@CNTs-NPP, other $\mathrm{Li}_{2} \mathrm{~S}_{\mathrm{n}}$ solutions with adsorbents have no significant change. This result indicates the stronger confinement from the carbon matrix toward the $\mathrm{Li}_{2} \mathrm{Se}_{\mathrm{n}}$ than $\mathrm{Li}_{2} \mathrm{~S}_{\mathrm{n}}$ [4, 43]. After adsorption experiments, the supernates were obtained and diluted for further UV-Vis absorption measurements. It can be observed from Fig. S8 that both the absorption intensity of $\mathrm{Li}_{2} \mathrm{~S}_{\mathrm{n}}$ and $\mathrm{Li}_{2} \mathrm{Se}_{\mathrm{n}}$ solution after adding the CF@CNTsNPP have a significant decline, confirming that the CF@ CNTs-NPP hybrid is indeed capable of strong capturing both the soluble $\mathrm{Li}_{2} \mathrm{~S}_{\mathrm{n}}$ and $\mathrm{Li}_{2} \mathrm{Se}_{\mathrm{n}}[44,45]$.

The chemical interaction between S/Se species and CF@ CNTs-NPP were excavated by FT-IR spectroscopy, which can unveil the change of functional groups in CF@CNTsNPP hybrid before and after adsorption. As shown in Fig. 3b, the fresh CF@CNTs-NPP shows the main peaks that are almost identical to NPP. Interestingly, there are some obvious changes in the FT-IR spectra of CF@CNTs-NPP after $\mathrm{Li}_{2} \mathrm{~S}_{\mathrm{n}}$ adsorption (denoted as $\mathrm{Li}_{2} \mathrm{~S}_{\mathrm{n}}-\mathrm{NPP}$ ) and after $\mathrm{Li}_{2} \mathrm{Se}_{\mathrm{n}}$ adsorption (denoted as $\mathrm{Li}_{2} \mathrm{Se}_{\mathrm{n}}-\mathrm{NPP}$ ). For the $\mathrm{Li}_{2} \mathrm{~S}_{\mathrm{n}}-\mathrm{NPP}$, all the peaks corresponding to $\mathrm{C}=\mathrm{O}$ in ester, $\mathrm{O}-\mathrm{C}-\mathrm{O}, \mathrm{C}-\mathrm{O}-\mathrm{H}$, and $\mathrm{C}-\mathrm{O}-\mathrm{C}$ become weak distinctly, suggesting the chemical reactions occurred between the $\mathrm{Li}_{2} \mathrm{~S}_{\mathrm{n}}$ and the electron-rich oxygen-containing functional groups in CF@CNTs-NPP $[46,47]$. In addition, these peaks in $\mathrm{Li}_{2} \mathrm{Se}_{n}-\mathrm{NPP}$ decrease more than those in $\mathrm{Li}_{2} \mathrm{~S}_{\mathrm{n}}-\mathrm{NPP}$, confirming the stronger chemical interaction of NPP with $\mathrm{Li}_{2} \mathrm{Se}_{\mathrm{n}}$ than $\mathrm{Li}_{2} \mathrm{~S}_{\mathrm{n}}$, which is consistent with the results of theoretical calculation.

To further explore the specific interactive relationship between $\mathrm{Li}_{2} \mathrm{~S}_{\mathrm{n}} / \mathrm{Li}_{2} \mathrm{Se}_{\mathrm{n}}$ and CF@CNTs-NPP, the surface chemical properties of $\mathrm{Li}_{2} \mathrm{~S}_{\mathrm{n}}, \mathrm{Li}_{2} \mathrm{Se}_{\mathrm{n}}, \mathrm{Li}_{2} \mathrm{~S}_{\mathrm{n}}-\mathrm{NPP}$, and $\mathrm{Li}_{2} \mathrm{Se}_{\mathrm{n}}-\mathrm{NPP}$ were further investigated by XPS. As presented in Fig. 3c, for the Li $1 \mathrm{~s}$ spectrum of the pristine $\mathrm{Li}_{2} \mathrm{~S}_{\mathrm{n}}$, the peak at $55.5 \mathrm{eV}$ is assigned to the $\mathrm{Li}-\mathrm{S}$ bond. After adsorption, the Li 1 s spectrum of $\mathrm{Li}_{2} \mathrm{~S}_{\mathrm{n}}$-NPP appears two peaks 
and undergoes a shift to a higher binding energy. The new peak located at $57.1 \mathrm{eV}$ is associated with the formation of $\mathrm{Li}-\mathrm{O}$ bond between the $\mathrm{Li}_{2} \mathrm{~S}_{\mathrm{n}}$ and the oxygen functional groups of NPP [48]. Meanwhile, the $\mathrm{S} 2 \mathrm{p}$ spectrum of $\mathrm{Li}_{2} \mathrm{~S}_{\mathrm{n}}$ shows two pairs of $\mathrm{S}$ doublets at 162 and $163 \mathrm{eV}$, corresponding to the terminal $\left(\mathrm{S}_{\mathrm{T}}{ }^{-1}\right)$ and bridge $\left(\mathrm{S}_{\mathrm{B}}{ }^{0}\right) \mathrm{S}$ atoms, respectively (Fig. 3d) [49-51]. Besides, the formation of thiosulfate with a negligible intensity may be caused by the oxidation of sulfur atom during XPS detection process [52]. By comparison, the $\mathrm{S}$ peaks from $\mathrm{Li}_{2} \mathrm{~S}_{\mathrm{n}}-\mathrm{NPP}$ exhibit a considerable shift to a higher energy range, suggesting the reduction of electron cloud density along the sulfur chains [53, 54]. Moreover, the significant contribution between 166 and $172 \mathrm{eV}$ is ascribed to thiosulfate and polythionate species formed by the redox reaction between the $\mathrm{Li}_{2} \mathrm{~S}_{\mathrm{n}}$ and the oxygen-containing functional groups in CF@CNTs-NPP [52, 55]. In Fig. 3e, the Se $3 d$ spectrum displays two peaks at 55.4 and $56.3 \mathrm{eV}$ attributed to the $\mathrm{Se} 3 \mathrm{~d}_{5 / 2}$ and $\mathrm{Se} 3 \mathrm{~d}_{3 / 2}$ states [56, 57], respectively, meanwhile the Li-Se bonds at $55.9 \mathrm{eV}$ can be observed because of the overlapped region of Se 3d spectrum and Li 1s spectrum [58]. After adsorption, the appearance of $\mathrm{Se}-\mathrm{O}$ and $\mathrm{Li}-\mathrm{O}$ bonds verify the chemical (a)

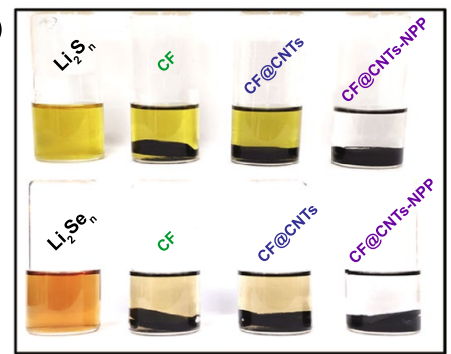

(c)

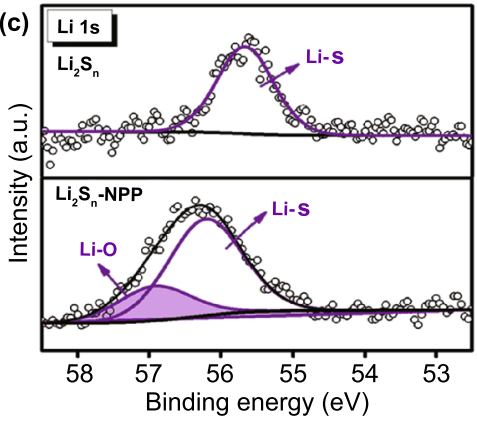

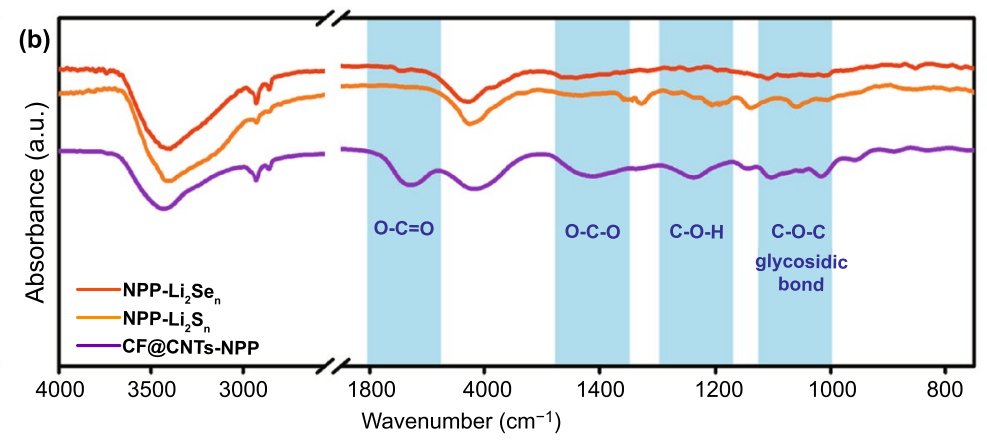
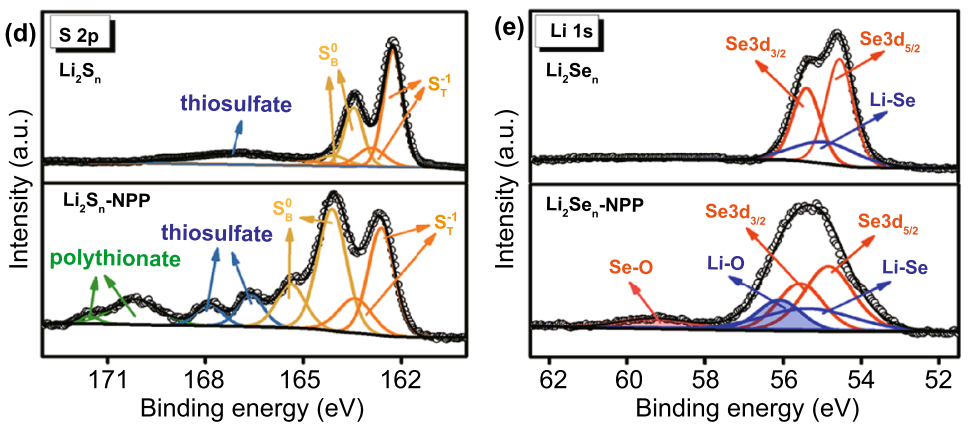

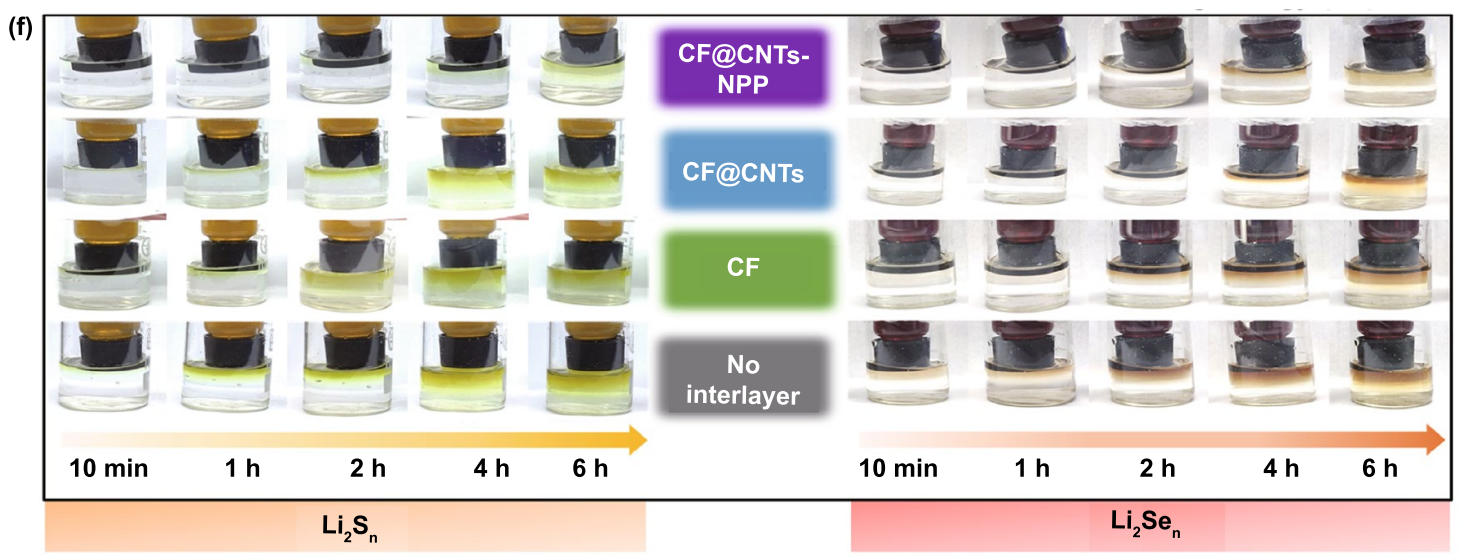

Fig. 3 a Optical photographs of $\mathrm{Li}_{2} \mathrm{~S}_{\mathrm{n}}$ and $\mathrm{Li}_{2} \mathrm{Se}_{\mathrm{n}}$ solutions contacted with CF, CF@CNTs, and CF@CNTs-NPP after 12 h. b FT-IR spectra of CF@CNTs-NPP, $\mathrm{Li}_{2} \mathrm{~S}_{\mathrm{n}}-\mathrm{NPP}$, and $\mathrm{Li}_{2} \mathrm{Se}_{\mathrm{n}}-\mathrm{NPP}$. High-resolution XPS c Li 1s and d S 2p spectra of $\mathrm{Li}_{2} \mathrm{~S}_{\mathrm{n}}$ and $\mathrm{Li}_{2} \mathrm{~S}_{\mathrm{n}}-\mathrm{NPP}$. e High-resolution XPS $\mathrm{Li}$ 1s spectra of $\mathrm{Li}_{2} \mathrm{Se}_{\mathrm{n}}$ and $\mathrm{Li}_{2} \mathrm{Se}_{\mathrm{n}}$-NPP. f Digital photographs of $\mathrm{Li}_{2} \mathrm{~S}_{\mathrm{n}}$ (left) and $\mathrm{Li}_{2} \mathrm{Se}_{\mathrm{n}}$ (right) diffusion at different rest times 
interaction between the $\mathrm{Li}_{2} \mathrm{Se}_{\mathrm{n}}$ and the oxygenic functional groups of NPP [58].

In order to visually demonstrate the distinctive capability of the CF@CNTs-NPP hybrid as an interlayer to capture both the $\mathrm{Li}_{2} \mathrm{~S}_{\mathrm{n}}$ and $\mathrm{Li}_{2} \mathrm{Se}_{\mathrm{n}}$, the diffusion experiments are implemented by using the test device displayed in Fig. S9. Because of the concentration difference and the gravity effect, the $\mathrm{Li}_{2} \mathrm{~S}_{\mathrm{n}} / \mathrm{Li}_{2} \mathrm{Se}_{\mathrm{n}}$ diffusion behavior can be observed by the color variation in the bottom of electrolyte. As shown in the left half of Fig. 3f, the tested bottle in the interlayer-free device exhibits a deep yellow color after $6 \mathrm{~h}$, manifesting a high content of $\mathrm{Li}_{2} \mathrm{~S}_{\mathrm{n}}$ and thus a fast $\mathrm{Li}_{2} \mathrm{~S}_{\mathrm{n}}$ diffusion. Gratifyingly, the electrolyte in the device equipped with CF@CNTs-NPP interlayer only turns into pale yellow after $6 \mathrm{~h}$, much lighter than that of other three samples, verifying the effective interception of CF@CNTs-NPP interlayer toward $\mathrm{Li}_{2} \mathrm{~S}_{\mathrm{n}}$. The similar results are embodied in $\mathrm{Li}_{2} \mathrm{Se}_{\mathrm{n}}$ diffusion tests, as shown in right half of Fig. 3f. Obviously, the device assembled with CF@CNTs-NPP interlayer only has a slight color change even after $6 \mathrm{~h}$. On the contrary, $\mathrm{Li}_{2} \mathrm{Se}_{\mathrm{n}}$ diffuses quickly in the device without interlayer, and the colorless electrolyte at the bottom bottles turns into reddish brown after $6 \mathrm{~h}$. All above diffusion tests reflect the effective adsorption of CF@CNTs-NPP interlayer, which can retard the diffusion and the shuttling of $\mathrm{Li}_{2} \mathrm{Se}_{\mathrm{n}} / \mathrm{Li}_{2} \mathrm{~S}_{\mathrm{n}}$.

To examine if there exists a promoting effect of the $\mathrm{CF} @$ CNTs-NPP toward $\mathrm{Li}_{2} \mathrm{~S}_{\mathrm{n}}$ conversion, $\mathrm{Li}_{2} \mathrm{~S}$ precipitation experiments were performed. As exhibited in Fig. $4 \mathrm{a}-\mathrm{c}$, the responsiveness of $\mathrm{Li}_{2} \mathrm{~S}$ nucleation on $\mathrm{CF} @ \mathrm{CNTs}-\mathrm{NPP}$ is earlier than that on CF@CNTs and CF, indicating the better catalytic promoting effect of CF@CNTs-NPP for $\mathrm{Li}_{2} \mathrm{~S}_{\mathrm{n}}$ transformation [59, 60]. Moreover, the CF@CNTs-NPP exhibits the highest precipitation current $(0.16 \mathrm{~mA})$ and conversion capacity of $141.59 \mathrm{mAh} \mathrm{g}^{-1}$ compared to the CF@ CNTs (0.13 mA, $\left.131.62 \mathrm{mAh} \mathrm{g}^{-1}\right)$ and CF (0.05 mA, 64.21 $\mathrm{mAh} \mathrm{g}^{-1}$ ). These results attest that the CF@CNTs-NPP can substantially reduce the overpotential of $\mathrm{Li}_{2} \mathrm{~S}$ nucleation and accelerate the interfacial electron transfer kinetics for $\mathrm{Li}_{2} \mathrm{~S}$ precipitation $[61,62]$. To better identify the potential catalytic effect of the CF@CNTs-NPP on enhancing the conversion of $\mathrm{Li}_{2} \mathrm{~S}_{\mathrm{n}}$ and $\mathrm{Li}_{2} \mathrm{Se}_{\mathrm{n}}$, symmetric cells were further assembled by adopting two selfsame electrodes with $\mathrm{Li}_{2} \mathrm{~S}_{6}$ and $\mathrm{Li}_{2} \mathrm{Se}_{6}$ electrolyte, respectively. The experimental symmetric cell employs two CF@CNTs-NPP electrodes, while the other two control cells respectively contain two $\mathrm{CF}$ and
CF@CNT electrodes. The cyclic voltammetry (CV) curves of these assembled symmetric cells were detected at a scan rate of $1 \mathrm{mV} \mathrm{s}^{-1}$. The $\mathrm{CV}$ curves of the symmetric cells with a $\mathrm{Li}_{2} \mathrm{~S}_{6} / \mathrm{Li}_{2} \mathrm{Se}_{6}$-free electrolyte were measured, which verifies no contribution to the capacitive current, as shown in Fig. 4d, e. In the presence of the CF@CNTs-NPP, the cells either with $\mathrm{Li}_{2} \mathrm{~S}_{6}$ (Fig. 4d) or with $\mathrm{Li}_{2} \mathrm{Se}_{6}$ (Fig. 4e) show the sharpest redox peaks together with the strongest current response when compared with the other control cells, implying the enhanced electrochemical reversibility along with favorable $\mathrm{Li}_{2} \mathrm{~S}_{\mathrm{n}}$ and $\mathrm{Li}_{2} \mathrm{Se}_{\mathrm{n}}$ redox conversion [63, 64].

To exhibit the availability of CF@CNTs-NPP, the electrochemical performance of $\mathrm{Li}_{-} \mathrm{SeS}_{2}$ coin cells with the CF@ CNTs-NPP as interlayers was tested using $\mathrm{SeS}_{2} / \mathrm{CNTs}$ composite cathode with a $70 \mathrm{wt} \% \mathrm{SeS}_{2}$ content (Fig. S10). For comparison, the cells without interlayers and with $\mathrm{CF}$ and CF@CNTs interlayers were also assembled with the same composite cathodes as the contrast samples. The $\mathrm{CV}$ curves of the four types of cells were conducted at a scanning rate of $0.1 \mathrm{mV} \mathrm{s}^{-1}$ with the voltage range of 1.7-2.8 V. As shown in Fig. 4f, the cell with CF@CNTs-NPP interlayer exhibits three cathodic peaks, corresponding to the typical successive lithiation conversion processes from $\mathrm{SeS}_{2}$ to soluble long-chain $\mathrm{Li}_{2} \mathrm{~S}_{\mathrm{n}}$ and long-chain $\mathrm{Li}_{2} \mathrm{Se}_{\mathrm{n}}$, then, to the final products of $\mathrm{Li}_{2} \mathrm{~S}_{2} / \mathrm{Li}_{2} \mathrm{~S}$ and $\mathrm{Li}_{2} \mathrm{Se}$. The anodic peak is considered to the gradual delithiation of $\mathrm{Li}_{2} \mathrm{~S}_{2} / \mathrm{Li}_{2} \mathrm{~S}$ and $\mathrm{Li}_{2} \mathrm{Se}$ [14]. Compared to the cells without interlayer and with $\mathrm{CF}$ interlayer, the cells with CF@CNTs-NPP and CF@CNTs interlayers show much higher peak currents, higher reduction potentials, and lower oxidation potentials, indicating the rapid redox kinetics associated with the excellent conductivity of the CF@CNTs skeleton. This is further testified by the reduction of charge-transfer resistance of the cells with CF@ CNTs-NPP and CF@CNTs interlayers due to the construction of CF@CNTs skeleton (Fig. S11) [65].

The initial discharge-charge curves of the four cells at $0.1 \mathrm{~A} \mathrm{~g}^{-1}$ are exhibited in Fig. $4 \mathrm{~g}$. Specifically, the cell with CF@CNTs-NPP interlayer shows four discharge plateaus at around 2.32, 2.17, 2.14, and $2.04 \mathrm{~V}$, ascribed to the generation of soluble high-order $\mathrm{Li}_{2} \mathrm{~S}_{\mathrm{n}}$ and $\mathrm{Li}_{2} \mathrm{Se}_{\mathrm{n}}$, then, the transformation to the final products of $\mathrm{Li}_{2} \mathrm{~S}_{2} / \mathrm{Li}_{2} \mathrm{~S}$ and $\mathrm{Li}_{2} \mathrm{Se}$. The four similar discharge platforms appear in the curve of the cell with CF@CNTs interlayer. However, there are only three plateaus in the discharge curves of the cell with CF interlayer and the cell without interlayer, implying the severe polarization and high resistance caused by the 
poor conductivity and weak adsorption to $\mathrm{Li}_{2} \mathrm{~S}_{\mathrm{n}}$ and $\mathrm{Li}_{2} \mathrm{Se}_{\mathrm{n}}$. Remarkably, the initial discharge and charge capacities of the cell with CF@CNTs-NPP interlayer are 1049 and 1050 $\mathrm{mAh} \mathrm{g}^{-1}$, respectively, which are higher than the cells with CF@CNTs (1012/1039 mAh g $\left.{ }^{-1}\right)$, CF interlayer (850/894 $\left.\mathrm{mAh} \mathrm{g}^{-1}\right)$ and without interlayer $\left(625 / 657 \mathrm{mAh} \mathrm{g}^{-1}\right)$, indicating that the relatively superior utilization of $\mathrm{SeS}_{2}$ can be achieved in the employment of CF@CNTs-NPP interlayer.

The enhanced redox kinetics of the cell with interlayer is further demonstrated by the excellent cycling response to continuous variation of current densities (Figs. 4h and S12). When cycled at $0.2,0.5,1,2,5$, and $10 \mathrm{~A} \mathrm{~g}^{-1}$, the cell with CF@CNTs-NPP interlayer delivers the average discharge capacities of $964,843,758,674,551$, and $448 \mathrm{mAh} \mathrm{g}^{-1}$, respectively, which is the highest capacity over $2 \mathrm{~A} \mathrm{~g}^{-1}$ in ever reported for $\mathrm{Li}-\mathrm{SeS}_{2}$ batteries, as summarized in Fig. $\mathrm{S} 13$. As the current density successively turns back to $0.2 \mathrm{~A}$ $\mathrm{g}^{-1}$, the capacity can rapidly restore to $910 \mathrm{mAh} \mathrm{g}^{-1}$, demonstrating the excellent high-rate response and reversibility of the cell. Attributed to the high conductivity of CF@CNTs
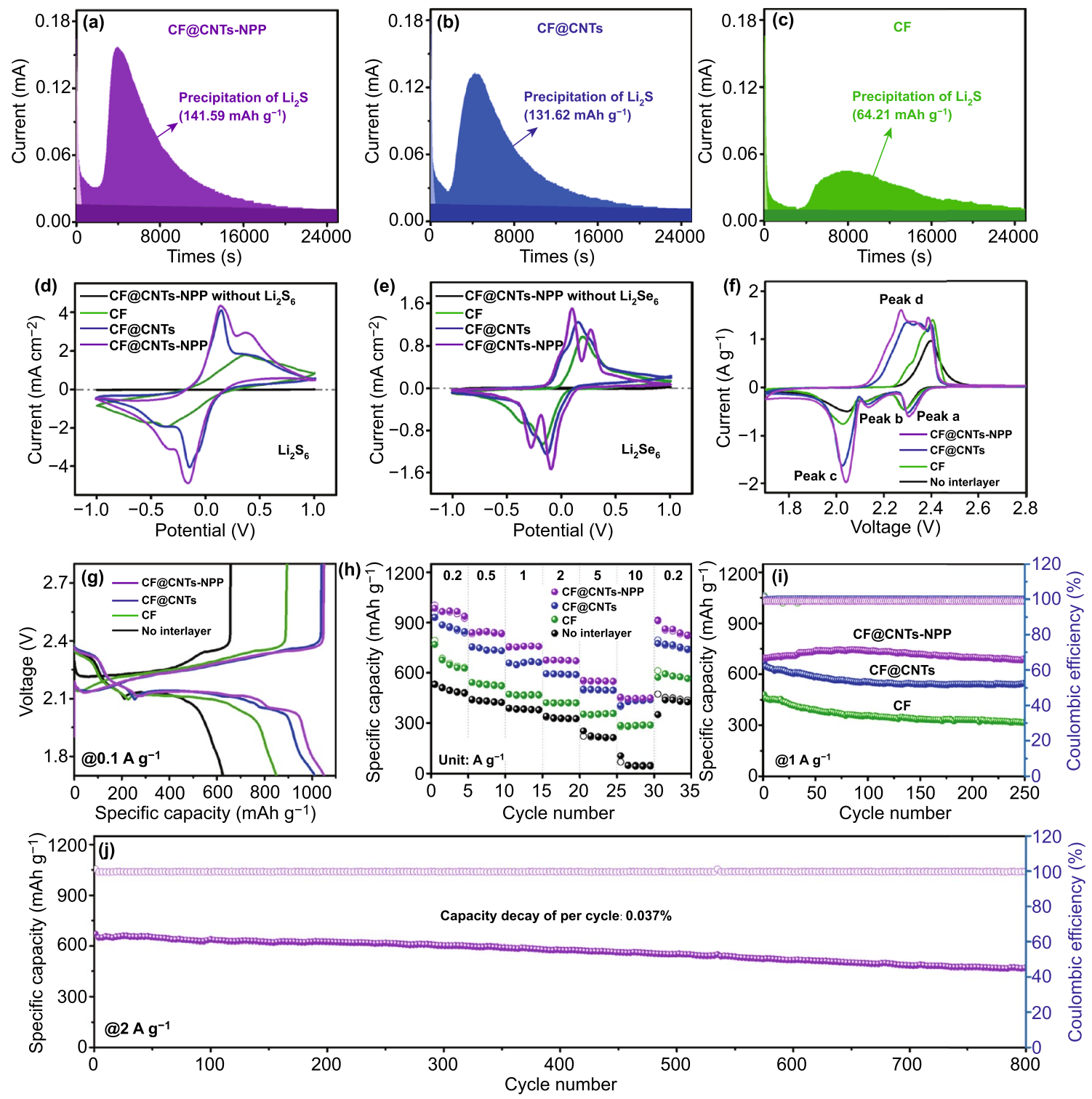

Fig. 4 Potentiostatic discharge profiles of cells with a CF@CNTs-NPP, b CF@CNTs and c CF at 2.05 V. CV curves of symmetric cells with different electrodes $\mathbf{d}$ with or without $0.2 \mathrm{M} \mathrm{Li}_{2} \mathrm{~S}_{6}$ and e with or without $0.2 \mathrm{M} \mathrm{Li}_{2} \mathrm{Se}_{6}$ at the scan rate of $1 \mathrm{mV} \mathrm{s}^{-1}$. f CV curves at the scan rate of $0.1 \mathrm{mV} \mathrm{s}^{-1}$. $\mathbf{g}$ Initial discharge-charge curves at $0.1 \mathrm{~A} \mathrm{~g}^{-1}$. $\mathbf{h}$ Rate capability. Cycling performance at $\mathbf{i} 1 \mathrm{~A} \mathrm{~g} \mathrm{~g}^{-1}$ and $\mathbf{j} 2 \mathrm{~A} \mathrm{~g}^{-1}$ under room temperature 
framework, the cell with CF@CNTs interlayer also exhibits good capacity retention from 880 to $427 \mathrm{mAh} \mathrm{g}^{-1}$ as the rate increases from 0.2 to $10 \mathrm{~A} \mathrm{~g}^{-1}$. Nevertheless, the capacity declines dramatically to $774 \mathrm{mAh} \mathrm{g}^{-1}$ when the current density reverts to $0.2 \mathrm{~A} \mathrm{~g}^{-1}$. In sharp contrast, the discharge capacity of the cell with CF interlayer fades sharply from 670 to $285 \mathrm{mAh} \mathrm{g}^{-1}$, while the cell without interlayer shows the worst capacity retention from 499 to $57 \mathrm{mAh} \mathrm{g}^{-1}$ when the rate increases from 0.2 to $10 \mathrm{~A} \mathrm{~g}^{-1}$. Apart from that, the comparison of cycle performance at a current density of $1 \mathrm{~A} \mathrm{~g}^{-1}$ is exhibited in Figs. $4 \mathrm{i}$ and S14. The cell without interlayer only exhibits an initial discharge capacity of 397 $\mathrm{mAh} \mathrm{g}^{-1}$ with unstable and low Coulombic efficiency in the latter part of the cycle, as depicted in Fig. S14. As shown in Fig. 4i, after the introduction of the CF, CF@CNTs, and CF@CNTs-NPP interlayers, the initial discharge capacities increase to 480,674 , and $696 \mathrm{mAh} \mathrm{g}^{-1}$, respectively, but the rapid capacity decay happened in the cells with $\mathrm{CF}$ and CF@CNTs interlayers over 250 cycles. Noticeably, the cell with CF@CNTs-NPP interlayer can still remain a high capacity of $688 \mathrm{mAh} \mathrm{g}^{-1}$ after 250 cycles with corresponding capacity retention ratio as high as $98.9 \%$, demonstrating its outstanding cycling stability. Furthermore, the long-term cycling test of the cell with CF@CNTs-NPP is displayed in Fig. 4j. It maintains the capacity of $470 \mathrm{mAh} \mathrm{g}^{-1}$ even after 800 cycles at $2 \mathrm{~A} \mathrm{~g} \mathrm{~g}^{-1}$ together with a stable CE of above $99 \%$, presenting a high capacity retention ratio of $70 \%$ and a low capacity decay of $0.037 \%$ per cycle. This indicates that the introduction of NPP into the hybrid interlayer is very effective to restrain the shuttling of polysulfide/polyselenide immediate and reduce the loss of active species for achieving a long lifespan in $\mathrm{Li}-\mathrm{SeS}_{2}$ batteries.

The serious self-discharge issue caused by the dissolution of intermediates into electrolyte is also a critical issue in $\mathrm{Li}_{-} \mathrm{SeS}_{2}$ batteries. Thus, we further tested the self-discharge behaviors of the cells with CF, CF@CNTs, and CF@CNTsNPP interlayers by implementing intermittent discharge/ charge tests with the rest time of $24 \mathrm{~h}$ after 50 cycles, $48 \mathrm{~h}$ after 100 cycles, $72 \mathrm{~h}$ after 150 cycles, $96 \mathrm{~h}$ after 200 cycles, and $120 \mathrm{~h}$ after 250 cycles. As shown in Fig. 5a, after the fitful discharge-charge tests of 300 cycles at $0.5 \mathrm{~A} \mathrm{~g}^{-1}$, the cell with CF@CNTs-NPP interlayer still keeps the capacity of $741 \mathrm{mAh} \mathrm{g}^{-1}$ and delivers a capacity retention of $87 \%$. Contrarily, the capacity retentions of the cells with CF@CNTs and $\mathrm{CF}$ interlayers are only $74 \%$ and $61 \%$, respectively. At the same time, the change of the open-circuit-voltages
(OCV) during $120 \mathrm{~h}$ rest time after 250 cycles is displayed in Fig. 5b. The OCV of the cell with CF interlayer started to drop significantly after $20 \mathrm{~h}$ rest time and decline sharply to $2.3 \mathrm{~V}$ after $120 \mathrm{~h}$. The drop in OCV of the cell with CF@ CNTs interlayer is ameliorated, which started to drop noticeably after $60 \mathrm{~h}$ rest time and finally decline to $2.33 \mathrm{~V}$. As for the cell with CF@CNTs-NPP interlayer, its OCV experiences only a very slow reduction process to $2.37 \mathrm{~V}$. Even after resting for $120 \mathrm{~h}$, the cell with CF@CNTs-NPP interlayer still remains a high discharge capacity of $741 \mathrm{mAh}$ $\mathrm{g}^{-1}$ and a low self-discharge ratio of only $1.5 \%$ (Fig. $5 \mathrm{c}$ ). In sharp contrast, the cells with CF@CNTs and CF interlayers exhibited high self-discharge ratio of $20.8 \%$ (Fig. 5d) and $21.9 \%$ (Fig. 5e), respectively. These results further manifest the effectivity of NPP in immobilizing soluble $\mathrm{Li}_{2} \mathrm{~S}_{\mathrm{n}} / \mathrm{Li}_{2} \mathrm{Se}_{\mathrm{n}}$ to suppress the self-discharge in $\mathrm{Li}-\mathrm{SeS}_{2}$ batteries.

The endurance under varying temperature atmosphere is of great importance for the practical application of batteries. Aiming to identify the thermal and frigid endurance performance, the cells with CF@CNTs-NPP interlayers were further tested at a raised temperature of $55^{\circ} \mathrm{C}$ and a subzero temperature of $-5{ }^{\circ} \mathrm{C}$. As shown in Fig. S15a, c, when cycled at $0.2,0.5,1,2,5$, and $10 \mathrm{~A} \mathrm{~g}^{-1}$, the cell is able to show the average discharge capacities of 903,758 , $661,604,551$, and $474 \mathrm{mAh} \mathrm{g}^{-1}$ at $55{ }^{\circ} \mathrm{C}$, while it also delivers the average discharge capacities of $611,501,397$, 255,142 , and $77 \mathrm{mAh} \mathrm{g}^{-1}$ at $-5{ }^{\circ} \mathrm{C}$, respectively. Besides, under such extreme temperature condition, it still shows exceptionally good cycling performance both at $55{ }^{\circ} \mathrm{C}$ (474 $\mathrm{mAh} \mathrm{g}^{-1}$ remaining after 250 cycles) and $-5{ }^{\circ} \mathrm{C}$ (329 $\mathrm{mAh} \mathrm{g}^{-1}$ ), as depicted in Fig. S15b and d. Nevertheless, the cells with the CF and CF@CNTs interlayers under raised and subzero temperatures both exhibit worse rate capability and cycle performance than the cell with CF@ CNTs-NPP interlayer.

To meet the demand of high energy density $\mathrm{Li}-\mathrm{SeS}_{2}$ batteries, a high $\mathrm{SeS}_{2}$ areal loading and a low electrolyteto-selenium sulfide $\left(\mathrm{E} / \mathrm{SeS}_{2}\right)$ ratio are commonly essential. However, most of recent studies on $\mathrm{Li}-\mathrm{SeS}_{2}$ batteries focused solely on the high capacity performance under a low $\mathrm{SeS}_{2}$ areal loading $\left(<2.0 \mathrm{mg} \mathrm{cm}^{-2}\right)$ and a high $\mathrm{E} / \mathrm{SeS}_{2}$ ratio $\left(>15 \mu \mathrm{L} \mathrm{mg}^{-1}\right)[16,66]$. As such, we further fabricated a series of high-areal-loading and low-E/SeS${ }_{2}$-ratio cells with the CF@CNTs-NPP interlayers. As shown in Fig. S16a, with a high areal $\mathrm{SeS}_{2}$ loading of $4.5 \mathrm{mg} \mathrm{cm}^{-2}$ and a relatively low $\mathrm{E} / \mathrm{SeS}_{2}$ ratio of $10 \mu \mathrm{L} \mathrm{mg}^{-1}$, the resultant cathode shows 

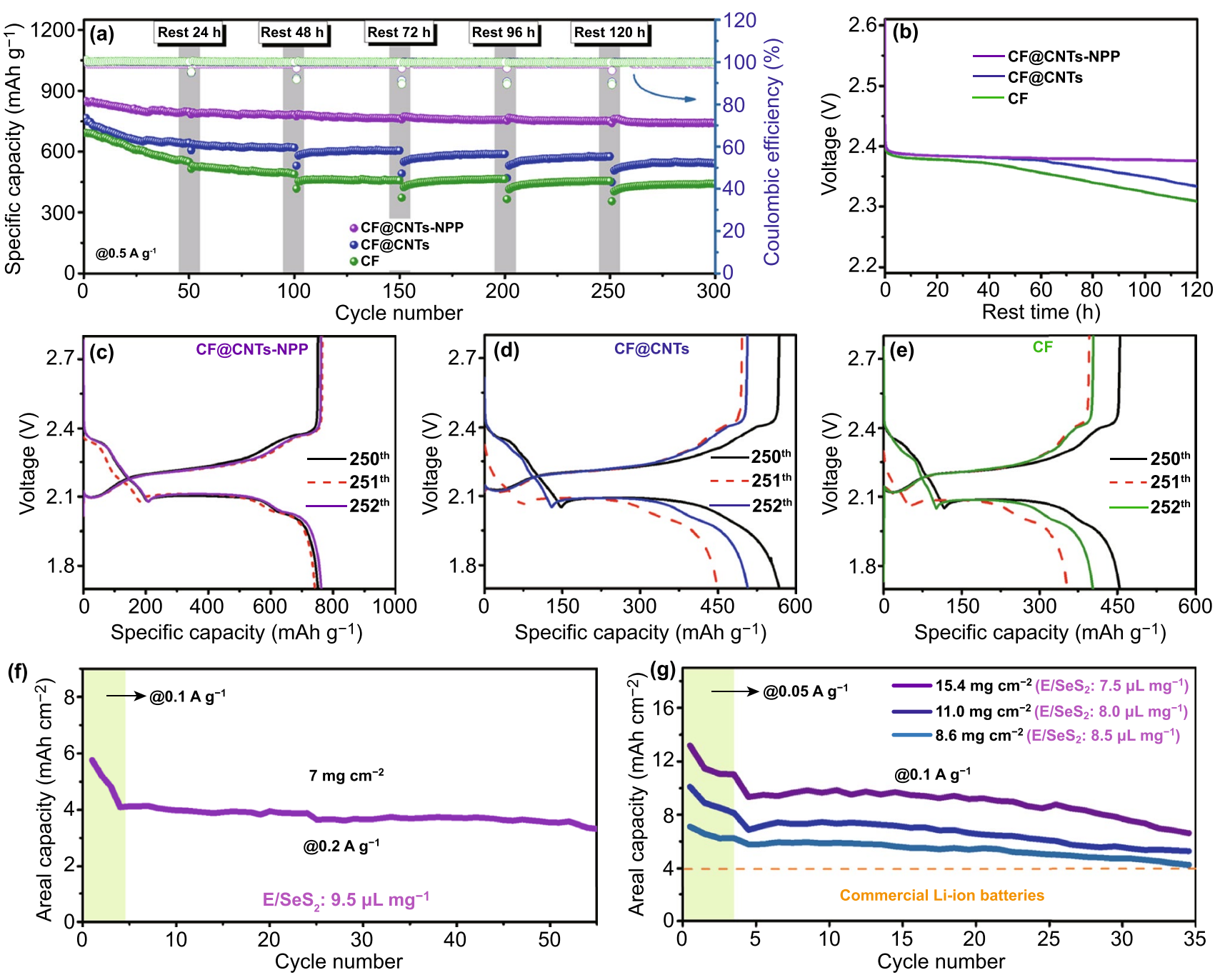

Fig. 5 a Cycling stability at $0.5 \mathrm{~A} \mathrm{~g}^{-1}$ after different rest periods of 24, 48, 72, 96, and $120 \mathrm{~h}$. b Open-circuit voltage curves of the cells during

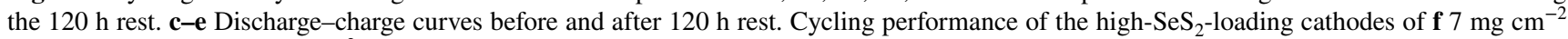
and $\mathbf{g} 8.6,11$, and $15.4 \mathrm{mg} \mathrm{cm}^{-2}$ of the $\mathrm{Li}-\mathrm{SeS}_{2}$ cells with the CF@CNTs-NPP interlayers

the reversible discharge capacities of $793,653,544$, and 499 $\mathrm{mAh} \mathrm{g}^{-1}$ as the current density increase from 0.1 to $1 \mathrm{~A} \mathrm{~g}^{-1}$. In addition, the cycling tests also show that a high reversible capacity of 600 and $450 \mathrm{mAh} \mathrm{g}^{-1}$ can be retained after 100 cycles at 0.2 and $0.5 \mathrm{~A} \mathrm{~g}^{-1}$ with a good capacity retention of $82.3 \%$ and $89.3 \%$, respectively (Fig. S16b). Moreover, by increasing the areal loading to $7.5 \mathrm{mg} \mathrm{cm}^{-2}$ along with a lower $\mathrm{E} / \mathrm{SeS}_{2}$ ratio of $9.5 \mu \mathrm{L} \mathrm{mg}^{-1}$, the cell with $\mathrm{CF} @$ CNTs-NPP interlayer still delivers a high initial discharge capacity of $550 \mathrm{mAh} \mathrm{g}^{-1}$ at $0.2 \mathrm{~A} \mathrm{~g}^{-1}$, and it can keep a stable cycling over 50 cycles (Fig. 5f). More remarkably, even when the $\mathrm{SeS}_{2}$ loadings were dramatically increased to 8.6, 11.0, $15.4 \mathrm{mg} \mathrm{cm}^{-2}$ while further lowering the $\mathrm{E} / \mathrm{SeS}_{2}$ ratio to $8.5,8.0$, and $7.5 \mu \mathrm{L} \mathrm{mg}^{-1}$, respectively, as shown in Fig. $5 \mathrm{~g}$, the cells are capable of achieving the areal capacities as high as $4.2,5.3$, and $6.6 \mathrm{mAh} \mathrm{cm}^{-2}$ after 30 cycles at 0.1 $\mathrm{A} \mathrm{g}^{-1}$, which manifest strong competitiveness compared to the state-of-the-art lithium-ion batteries.

In order to gain an insight into the adsorption and conversion of CF@CNTs-NPP interlayer to $\mathrm{Li}_{2} \mathrm{~S}_{\mathrm{n}}$ and $\mathrm{Li}_{2} \mathrm{Se}_{\mathrm{n}}$, operando characterization with in situ Raman spectroscopy was tested to track the existence and transformation of $\mathrm{Li}_{2} \mathrm{~S}_{\mathrm{n}}$ and $\mathrm{Li}_{2} \mathrm{Se}_{\mathrm{n}}$ on the CF@CNTs-NPP interlayer during the overall redox process, and Fig. 6a presents the tested cell configuration. As shown in Fig. 6b, c, during the early stage of the first discharge process, it is clearly observed 
that the $\mathrm{Li}_{2} \mathrm{~S}_{\mathrm{n}}$ including $\mathrm{Li}_{2} \mathrm{~S}_{6}, \mathrm{Li}_{2} \mathrm{~S}_{4}$ and $\mathrm{Li}_{2} \mathrm{~S}_{8}$ can be easily determined by their characteristic peaks located at 107,398, and $453 \mathrm{~cm}^{-1}$ in the Raman spectra [67, 68]. Moreover, the active anionic free radicals of $\mathrm{S}_{7}{ }^{-}, \mathrm{S}_{5}{ }^{-}$, and $\mathrm{S}_{3}{ }^{-}$centered at $533 \mathrm{~cm}^{-1}$ are observed [69]. Meanwhile, the characteristic peaks of chain-liked $\mathrm{Se}_{\mathrm{n}}{ }^{2-}\left(260 \mathrm{~cm}^{-1}\right)$ and active anionic free radical $\mathrm{Se}_{2}{ }^{-}\left(320-350 \mathrm{~cm}^{-1}\right)$ are also observed [70, 71]. All above results indicate that the $\mathrm{Li}_{2} \mathrm{~S}_{\mathrm{n}}$ and $\mathrm{Li}_{2} \mathrm{Se}_{\mathrm{n}}$ generated during the early stage of the first discharge process can be well anchored by the CF@CNTs-NPP interlayer. With (a) Laser

(a)

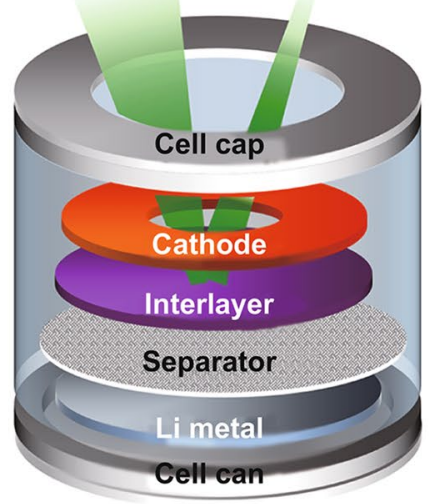

(d)

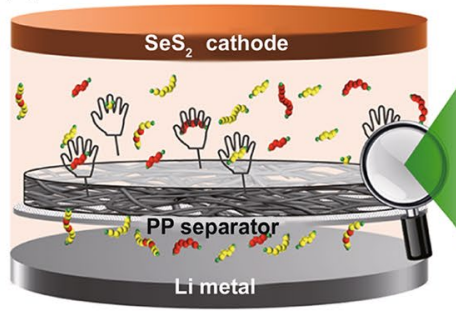

(e)

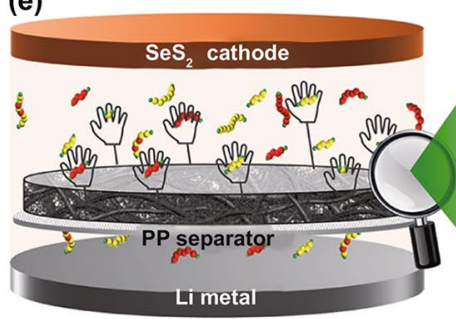

(f)

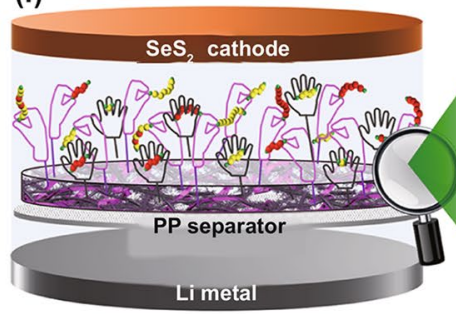

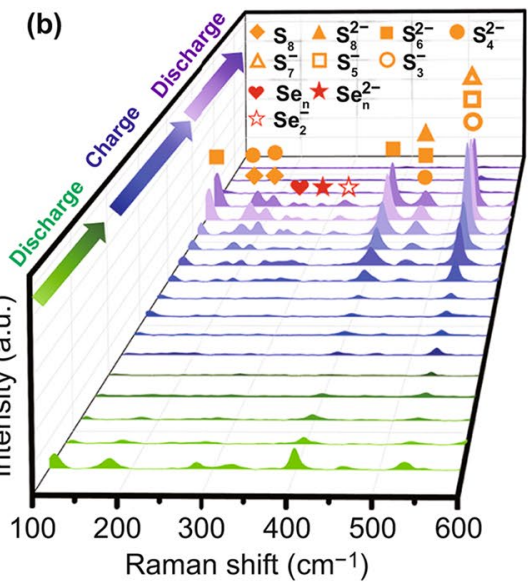
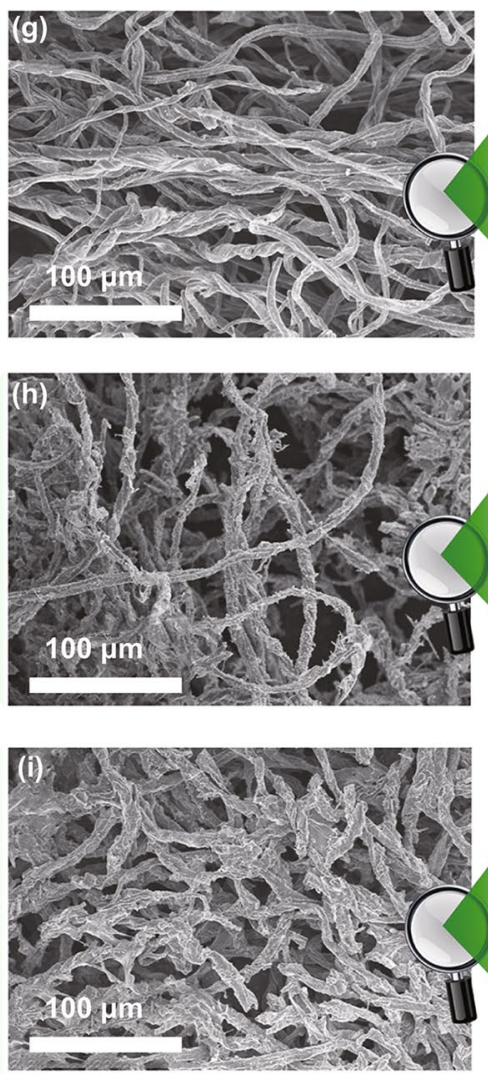
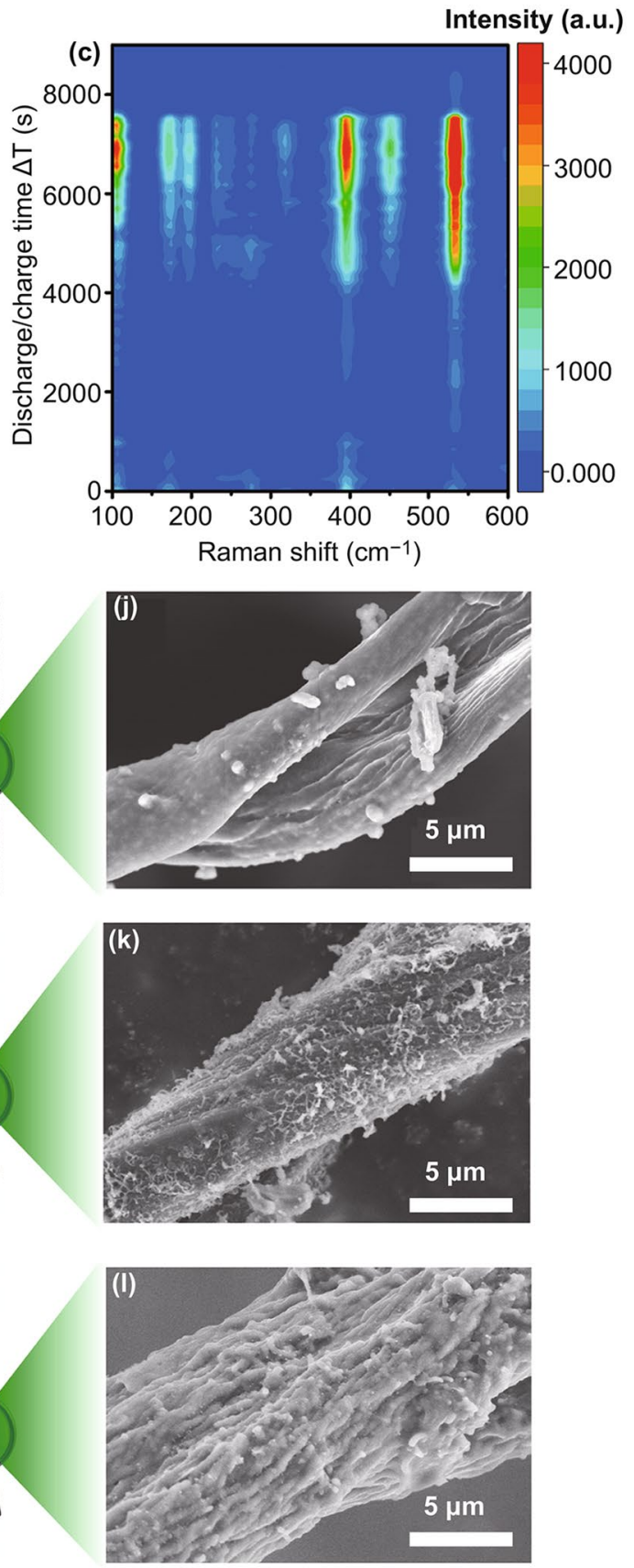

Fig. 6 a Cell configuration for Operando Raman test; b Operando Raman spectra and $\mathbf{c}$ the corresponding contour plot at different discharge and charge states. Schematic illustration of the operation of the Li-SeS ${ }_{2}$ batteries with $\mathbf{d}$ CF, e CF@CNTs, f CF@ CNTs-NPP interlayers and $\mathbf{g}-\mathbf{I}$ the corresponding FESEM images of different interlayers toward the cathodes after 100 cycles 
the discharge process, the peaks of $\mathrm{Li}_{2} \mathrm{~S}_{\mathrm{n}}$ and $\mathrm{Li}_{2} \mathrm{Se}_{\mathrm{n}}$ display a gradual disappearance, demonstrating that the $\mathrm{Li}_{2} \mathrm{~S}_{\mathrm{n}}$ and $\mathrm{Li}_{2} \mathrm{Se}_{\mathrm{n}}$ have been converted to $\mathrm{Li}_{2} \mathrm{~S}_{2} / \mathrm{Li}_{2} \mathrm{~S}$ and $\mathrm{Li}_{2} \mathrm{Se}$. During the following charge process, the $\mathrm{Li}_{2} \mathrm{~S}_{\mathrm{n}}$ and $\mathrm{Li}_{2} \mathrm{Se}_{\mathrm{n}}$ signals regenerate along with new peaks corresponding to the $S_{8}$ $\left(170-200 \mathrm{~cm}^{-1}\right)$ [69] and chain-like $\mathrm{Se}_{\mathrm{n}}\left(230-260 \mathrm{~cm}^{-1}\right)$ [58, 72], declaring that both the $\mathrm{Li}_{2} \mathrm{~S}_{\mathrm{n}}$ and $\mathrm{Li}_{2} \mathrm{Se}_{\mathrm{n}}$ trapped on the CF@CNTs-NPP interlayer are able to experience a reversible electrochemical conversion. During the second discharge process, the peaks about $\mathrm{Li}_{2} \mathrm{~S}_{\mathrm{n}}$ and $\mathrm{Li}_{2} \mathrm{Se}_{\mathrm{n}}$ become stronger than the first discharge process and gradually disappeared again, further confirming the powerful immobilization and conversion of CF@CNTs-NPP interlayer to $\mathrm{Li}_{2} \mathrm{~S}_{\mathrm{n}}$ and $\mathrm{Li}_{2} \mathrm{Se}_{\mathrm{n}}$.

To further verify the correlation of the adsorption function and structural stability of interlayers with the electrochemical performances of $\mathrm{Li}-\mathrm{SeS}_{2}$ batteries, a simplified model displaying the difference between the function of three kinds of interlayers in the immobilization process of $\mathrm{Li}_{2} \mathrm{~S}_{\mathrm{n}}$ ' $\mathrm{Li}_{2} \mathrm{Se}_{\mathrm{n}}$ is illustrated in Fig. 6d-f. As shown in Fig. 6d, the soluble $\mathrm{Li}_{2} \mathrm{~S}_{\mathrm{n}} / \mathrm{Li}_{2} \mathrm{Se}_{\mathrm{n}}$ can be restricted in the cathode region slightly because of the introduction of CF interlayer. When CNTs are incorporated into the CF interlayer, as shown in Fig. 6e, the CF@CNTs interlayer possesses more abundant physical adsorption sites and higher electric conductivity, which work as a physical barrier for confining $\mathrm{Li}_{2} \mathrm{~S}_{\mathrm{n}} / \mathrm{Li}_{2} \mathrm{Se}_{\mathrm{n}}$ and a "vice-electrode" with fast electronic transport channel to realize the reuse of $\mathrm{Li}_{2} \mathrm{~S}_{\mathrm{n}} / \mathrm{Li}_{2} \mathrm{Se}_{\mathrm{n}}$ [73]. As for CF@ CNTs-NPP interlayer (Fig. 6f), it not only has the inherent functions from CF@CNTs scaffold, but also affords a strong chemisorption to immobilize $\mathrm{Li}_{2} \mathrm{~S}_{\mathrm{n}} / \mathrm{Li}_{2} \mathrm{Se}_{\mathrm{n}}$ owing to the ample oxygenic functional groups of NPP, thus retarding the shuttle effect and prolonging the lifespan of $\mathrm{Li}-\mathrm{SeS}_{2}$ batteries. This can be corroborated by the morphologies of three kinds of interlayers after 100 cycles in Fig. $6 \mathrm{~g}-\mathrm{i}$. As shown in Fig. 6j-1, compared to the interlayers before cycles, all three kinds of interlayers still keep the interwoven fiber structure except the increase of surface roughness, which is attributed to the deposition of $\mathrm{S} / \mathrm{Se}$ species. As clearly shown in Fig. 61, the diameters of fibers in CF@CNTs-NPP interlayer enlarge markedly toward the cathode side, but it is not obvious toward the separator side (Fig. S17), testifying the efficient absorptivity of NPP to $\mathrm{Li}_{2} \mathrm{~S}_{\mathrm{n}} / \mathrm{Li}_{2} \mathrm{Se}_{\mathrm{n}}$. In contrast, the fibers in CF (Fig. 6j) and CF@CNTs interlayer toward the cathode side (Fig. 6k) have nearly unchanged.
The element distribution of the CF@CNTs-NPP interlayer toward the cathode and separator was further inquired by energy-dispersive X-ray (EDX) system. Based on the elemental mapping results, as shown in Fig. S18, distinct sulfur and selenium signals with a homogeneous distribution can be clearly observed in the CF@CNTs-NPP interlayer toward the cathode side, while the signals of sulfur and selenium are relatively weaker toward the separator side. Besides, the component ratios of the three cycled interlayers are shown in Fig. S19. The CF@CNTs-NPP interlayer toward the cathode side possesses the highest sulfur and selenium mass content, suggesting that the CF@CNTs-NPP interlayer effectively blocks the dissolution and shuttling of soluble $\mathrm{Li}_{2} \mathrm{~S}_{\mathrm{n}} / \mathrm{Li}_{2} \mathrm{Se}_{\mathrm{n}}$ so as to largely immobilize and confine them in the cathode side, which leads to reduced loss of the active species and enhanced lifespan of $\mathrm{Li}-\mathrm{SeS}_{2}$ batteries.

In addition, the structural stability of lithium (Li) metal in the anode is also crucial to the electrochemical performances of $\mathrm{Li}-\mathrm{SeS}_{2}$ batteries. To explore the relevance of the adsorption function of NPP with the structural stability of solid electrolyte interphase (SEI) and Li metal, the surface morphologies and element distribution of the Li metal in different kinds of $\mathrm{Li}-\mathrm{SeS}_{2}$ cells after 10 cycles at $1 \mathrm{~A} \mathrm{~g}^{-1}$ were conducted by field-emission scanning electron microscopy with energy-dispersive X-ray (EDX) system. As shown in Fig. S20a-h, the surface of the Li metal in cell with CF@ CNTs-NPP interlayer is relatively smooth and compact, while the cells with CF@CNTs and CF interlayers and the cell without interlayer all exhibit corrosive and scraggy surface of $\mathrm{Li}$ metal. Besides, the component ratios of the four kinds of cycled Li metal are shown in Fig. S20i-l. The Li metal of the cell with CF@CNTs-NPP interlayer possesses the lowest sulfur and almost undetectable selenium mass content. All above results suggest that the CF@CNTs-NPP interlayer can effectively block the dissolution and shuttling of soluble $\mathrm{Li}_{2} \mathrm{~S}_{\mathrm{n}} / \mathrm{Li}_{2} \mathrm{Se}_{\mathrm{n}}$ so as to largely alleviate the depletion of $\mathrm{LiNO}_{3}$ and the corrosion of fresh $\mathrm{Li}$, contributing to stable SEI and significantly improved lifespan of $\mathrm{Li}-\mathrm{SeS}_{2}$ batteries under practical conditions [74-76].

The outstanding performance of the CF@CNTs-NPP interlayer in high-SeS $\mathrm{S}_{2}$-loading and low-E/SeS $\mathrm{S}_{2}$-ratio coin cells inspired us to further investigate the performance in pouch cells, which is a prerequisite for realizing practical application of $\mathrm{Li}-\mathrm{SeS}_{2}$ batteries. As such, $\mathrm{Li}-\mathrm{SeS}_{2}$ pouch cells with the CF@CNTs-NPP interlayers were readily 
assembled with a size of $2 \times 4 \mathrm{~cm}^{2}$ and a typical $\mathrm{SeS}_{2}$ loading of $2.5 \mathrm{mg} \mathrm{cm}^{-2}$ with a much lower $\mathrm{E}^{-\mathrm{SeS}_{2}}$ ratio of 6 $\mu \mathrm{L} \mathrm{mg}{ }^{-1}$, as illustrated in Fig. 7a. In order to confirm the stability of this pouch cell configuration, the electrochemical impedance spectroscopy (EIS) curves under various bending states are given in Fig. 7c. Surprisingly, the charge-transfer resistance of the pouch cell is lower than that of the coin cell and keeps around $15 \Omega$, which is due to the intimate contact between the electrodes and electrolyte as well as the fast charge-transfer dynamics [77, 78]. Additionally, the Li-SeS 2 pouch cell is able to yield an output voltage of $2.857 \mathrm{~V}$
(Fig. 7b) that can light up a "SCU" device containing 93 red light-emitting diodes (LEDs) under various bending states, indicating its outstanding flexibility and stability (Fig. 7d). Furthermore, as exhibited in Fig. 7e, f, the $\mathrm{Li}-\mathrm{SeS}_{2}$ pouch cell exhibits a good rate capability with high discharge capacities of 1066, 879, 824, 764, and $701 \mathrm{mAh} \mathrm{g}^{-1}$ at 0.05 , $0.1,0.2,0.5$, and $1 \mathrm{~A} \mathrm{~g}^{-1}$, respectively, corresponding to low electrolyte-to-capacity ratio of $\approx 5.6,6.8,7.2,7.8$, and 8.5 $\mu \mathrm{L}(\mathrm{mAh})^{-1}$ and $\approx 79 \%, 65 \%, 61 \%, 57 \%$, and $52 \%$ of $\mathrm{SeS}_{2}$ utilization efficiency. Meanwhile, the subsequent cycling test at $0.5 \mathrm{~A} \mathrm{~g}^{-1}$ shows that the pouch cell delivers a high
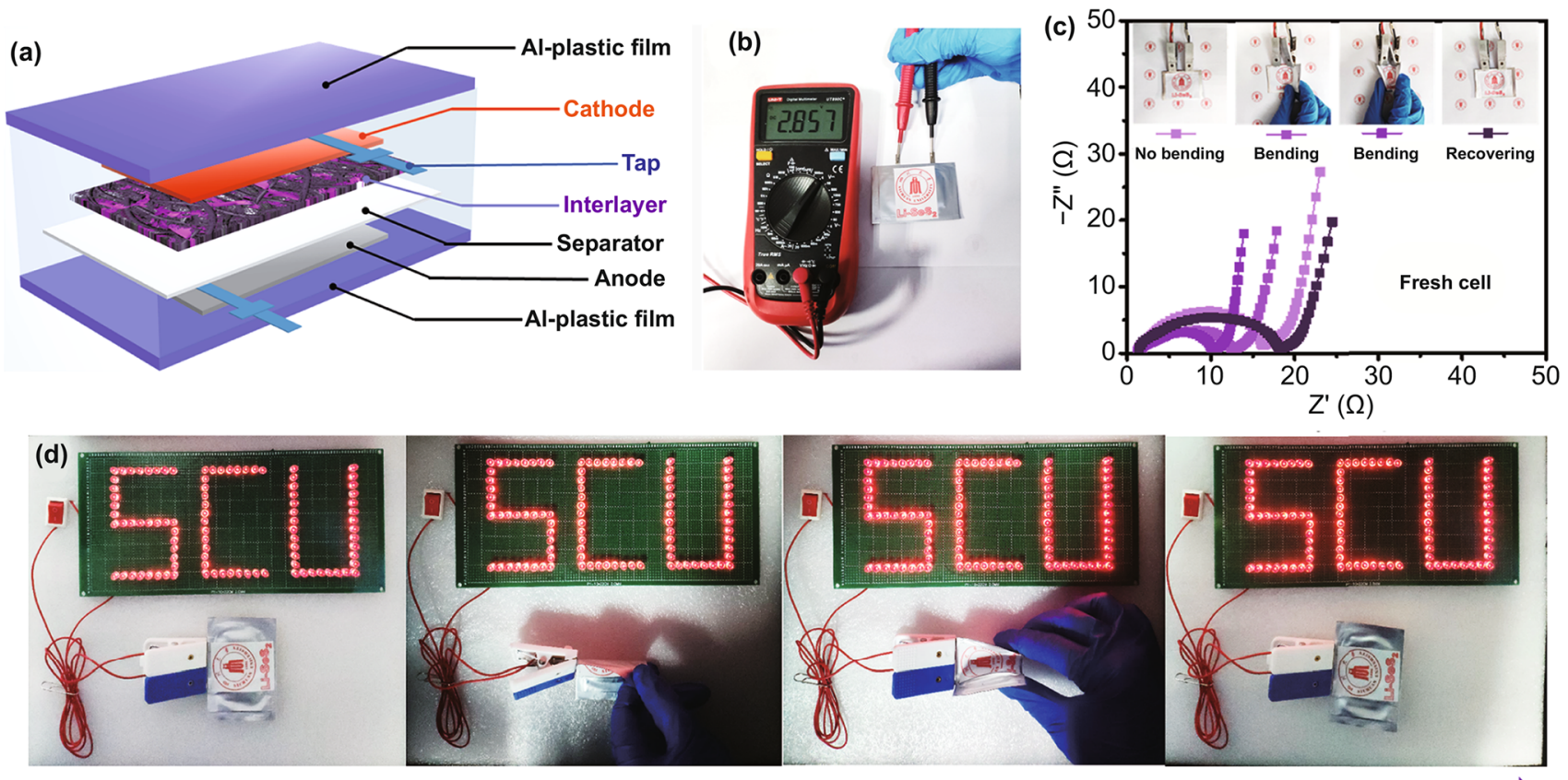

No bending

(e)

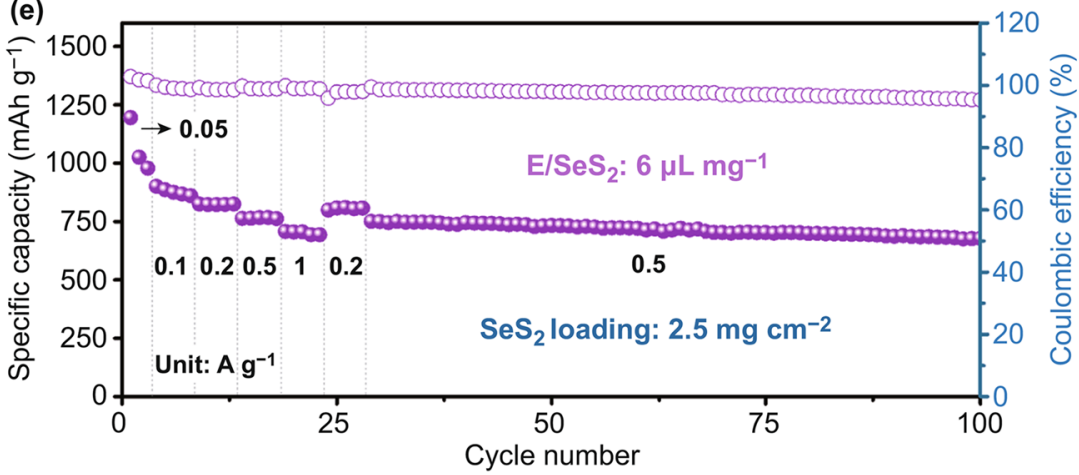

Recovering

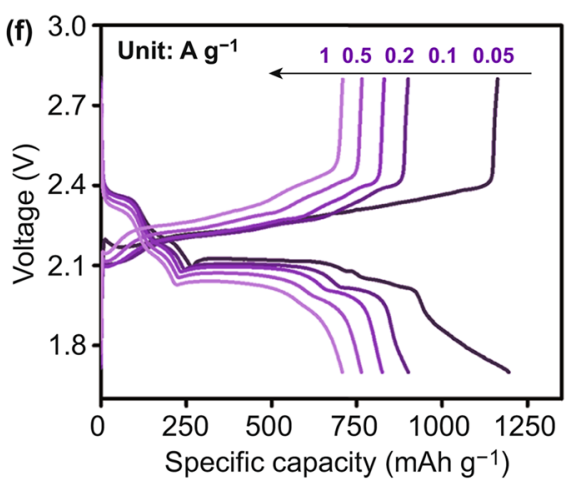

Fig. 7 a Schematic diagram and b the open-circuit voltage of a Li-SeS 2 pouch cell with the CF@CNTs-NPP interlayer. c Nyquist plots of the pouch cell before and after bending. d Demonstration of the pouch cell under various bending states to continuously light up the red light-emitting diodes (LED). e Electrochemical performance and $\mathbf{f}$ typical discharge-charge curves of the pouch cell at various current densities 
discharge capacity of $751 \mathrm{mAh} \mathrm{g}^{-1}$ and retains a satisfying capacity retention of $90.1 \%$ after 70 cycles. Notably, this is corresponding to a relatively low electrolyte-to-capacity ratio of $\approx 7.8 \mu \mathrm{L}(\mathrm{mA} \mathrm{h})^{-1}$, indicating a decent utilization of $\mathrm{SeS}_{2}$ (over 55\%) even under operation with a low $\mathrm{E} / \mathrm{SeS}_{2}$ ratio $\left(6 \mu \mathrm{L} \mathrm{mg}^{-1}\right)$. This implies the great potential of $\mathrm{CF} @$ CNTs-NPP interlayers for practical applications in working $\mathrm{Li}-\mathrm{SeS}_{2}$ batteries.

\section{Conclusions}

In summary, under the guidance of theoretical calculations, we have developed a feasible and simple protocol to engineer a $\mathrm{Li}_{2} \mathrm{~S}_{\mathrm{n}} / \mathrm{Li}_{2} \mathrm{Se}_{\mathrm{n}}$-regulating interlayer through depositing the natural NPP onto a 3D double-carbon conductive scaffold for high-performance $\mathrm{Li}-\mathrm{SeS}_{2}$ batteries. Benefiting from the ample oxygenic functional groups, NPP can provide a potent chemical adsorption toward $\mathrm{Li}_{2} \mathrm{~S}_{\mathrm{n}} / \mathrm{Li}_{2} \mathrm{Se}_{\mathrm{n}}$ based on the Lewis base chemical interaction and thereby effectively restrict the shuttling effect. Meanwhile, with the aid of the 3D open double-carbon conductive framework, the CF@CNTs-NPP as polysulfide/polyselenide shielding interlayer demonstrates effective promoting function to facilitate the $\mathrm{Li}_{2} \mathrm{~S}_{\mathrm{n}} / \mathrm{Li}_{2} \mathrm{Se}_{\mathrm{n}}$ conversion, improve their redox kinetics, and enhance the $\mathrm{SeS}_{2}$ utilization efficiency. As a result, the cells assembled with the CF@CNTs-NPP interlayers show ultrahigh rate capability, durable cycling lifespan, and high areal capacity even at high $\mathrm{SeS}_{2}$ loading. More meaningfully, the pouch cells with high $\mathrm{SeS}_{2}$ loading and low $\mathrm{E} / \mathrm{SeS}_{2}$ ratio have been successfully demonstrated to possess remarkable advantages in outstanding flexibility, high specific capacity, and stable cycling life. This work would manifest a prospective design and engineering protocol to develop low-cost, convenient, and feasible $\mathrm{Li}-\mathrm{SeS}_{2}$ batteries for practical applications.

Acknowledgements Y. Z. and M. W. contributed equally to this work. This work was supported by the National Key Research \& Development Program of China (2018YFB0104200), the National Natural Science Foundation of China (201878192 and 51904193). The authors acknowledge Dr. Lingzhu Yu and Guolong Meng from the National Engineering Research Center for Biomaterials at Sichuan University for FESEM measurements. We would also grateful to Ceshigo (www.ceshigo.com) for XPS characterization and DFT calculations.

Open Access This article is licensed under a Creative Commons Attribution 4.0 International License, which permits use, sharing, adaptation, distribution and reproduction in any medium or format, as long as you give appropriate credit to the original author(s) and the source, provide a link to the Creative Commons licence, and indicate if changes were made. The images or other third party material in this article are included in the article's Creative Commons licence, unless indicated otherwise in a credit line to the material. If material is not included in the article's Creative Commons licence and your intended use is not permitted by statutory regulation or exceeds the permitted use, you will need to obtain permission directly from the copyright holder. To view a copy of this licence, visit http://creativecommons.org/licenses/by/4.0/.

Supplementary Information The online version contains supplementary material available at https://doi.org/10.1007/ s40820-021-00629-z.

\section{References}

1. R. Fang, S. Zhao, Z. Sun, D.W. Wang, H.M. Cheng et al., More reliable lithium-sulfur batteries: status, solutions and prospects. Adv. Mater. 29(48), 1606823 (2017). https://doi. org/10.1002/adma.201606823

2. W. Ren, W. Ma, S. Zhang, B. Tang, Recent advances in shuttle effect inhibition for lithium sulfur batteries. Energy Storage Mater. 23, 707-732 (2019). https://doi.org/10.1016/j.ensm. 2019.02.022

3. A. Eftekhari, The rise of lithium-selenium batteries. Sustain. Energy Fuels 1(1), 14-29 (2017). https://doi.org/10.1039/ c6se00094k

4. G.-L. Xu, J. Liu, R. Amine, Z. Chen, K. Amine, Selenium and selenium-sulfur chemistry for rechargeable lithium batteries: interplay of cathode structures, electrolytes, and interfaces. ACS Energy Lett. 2(3), 605-614 (2017). https://doi.org/10. 1021/acsenergylett.6b00642

5. X. Gu, C. Lai, One dimensional nanostructures contribute better $\mathrm{Li}-\mathrm{S}$ and $\mathrm{Li}-\mathrm{Se}$ batteries: Progress, challenges and perspectives. Energy Storage Mater. 23, 190-224 (2019). https:// doi.org/10.1016/j.ensm.2019.05.013

6. A. Abouimrane, D. Dambournet, K.W. Chapman, P.J. Chupas, W. Weng et al., A new class of lithium and sodium rechargeable batteries based on selenium and selenium-sulfur as a positive electrode. J. Am. Chem. Soc. 134(10), 4505-4508 (2012). https://doi.org/10.1021/ja211766q

7. J. He, W. Lv, Y. Chen, J. Xiong, K. Wen et al., Direct impregnation of $\mathrm{SeS}_{2}$ into a MOF-derived 3D nanoporous $\mathrm{Co}-\mathrm{N}-\mathrm{C}$ architecture towards superior rechargeable lithium batteries. J. Mater. Chem. A 6(22), 10466-10473 (2018). https://doi.org/ $10.1039 / \mathrm{c} 8 \mathrm{ta} 02434 \mathrm{k}$

8. M. Wang, Y. Guo, B. Wang, H. Luo, X. Zhang et al., An engineered self-supported electrocatalytic cathode and dendritefree composite anode based on 3D double-carbon hosts for advanced $\mathrm{Li}-\mathrm{SeS}_{2}$ batteries. J. Mater. Chem. A 8(6), 29692983 (2020). https://doi.org/10.1039/c9ta11124g

9. Y. Cui, A. Abouimrane, J. Lu, T. Bolin, Y. Ren et al., (De)Lithiation mechanism of $\mathrm{Li}_{\mathrm{SeS}}(\mathrm{x}=0-7)$ batteries determined 
by in situ synchrotron X-ray diffraction and X-ray absorption spectroscopy. J. Am. Chem. Soc. 135(21), 8047-8056 (2013). https://doi.org/10.1021/ja402597g

10. Z. Zhang, S. Jiang, Y. Lai, J. Li, J. Song et al., Selenium sulfide@mesoporous carbon aerogel composite for rechargeable lithium batteries with good electrochemical performance. J. Power Sources 284, 95-102 (2015). https://doi.org/10. 1016/j.jpowsour.2015.03.019

11. J. Hu, H. Zhong, X. Yan, L. Zhang, Confining selenium disulfide in 3D sulfur-doped mesoporous carbon for rechargeable lithium batteries. Appl. Surf. Sci. 457, 705-711 (2018). https://doi.org/10.1016/j.apsusc.2018.06.296

12. H. Zhang, L. Zhou, X. Huang, H. Song, C. Yu, Encapsulation of selenium sulfide in double-layered hollow carbon spheres as advanced electrode material for lithium storage. Nano Res. 9(12), 3725-3734 (2016). https://doi.org/10.1007/ s12274-016-1243-2

13. J. Hu, Y. Ren, L. Zhang, Dual-confined $\mathrm{SeS}_{2}$ cathode based on polyaniline-assisted double-layered $\mathrm{micro} / \mathrm{mesoporous} \mathrm{car-}$ bon spheres for advanced $\mathrm{Li}-\mathrm{SeS}_{2}$ battery. J. Power Sources 455, 227955 (2020). https://doi.org/10.1016/j.jpowsour.2020. 227955

14. Z. Li, J. Zhang, H.B. Wu, X.W.D. Lou, An improved Li-SeS battery with high energy density and long cycle life. Adv. Energy Mater. 7(15), 1700281 (2017). https://doi.org/10.1002/ aenm.201700281

15. Z. Li, J. Zhang, B.Y. Guan, X.W.D. Lou, Mesoporous carbon@titanium nitride hollow spheres as an efficient $\mathrm{SeS}_{2}$ host for advanced $\mathrm{Li}_{-} \mathrm{SeS}_{2}$ batteries. Angew. Chem. Int. Ed. 56(50), 16003-16007 (2017). https://doi.org/10.1002/anie.201709176

16. T. Chen, W. Kong, M. Fan, Z. Zhang, L. Wang et al., Chelation-assisted formation of multi-yolk-shell $\mathrm{Co}_{4} \mathrm{~N} @$ carbon nanoboxes for self-discharge-suppressed high-performance Li-SeS 2 batteries. J. Mater. Chem. A 7(35), 20302-20309 (2019). https://doi.org/10.1039/c9ta07127j

17. Y. Zhang, Y. Guo, B. Wang, Y. Wei, P. Jing et al., An integrated hybrid interlayer for polysulfides/selenides regulation toward advanced $\mathrm{Li}-\mathrm{SeS}_{2}$ batteries. Carbon 161, 413-422 (2020). https://doi.org/10.1016/j.carbon.2020.01.102

18. J. Zhang, Z. Li, X.W.D. Lou, A freestanding selenium disulfide cathode based on cobalt disulfide-decorated multichannel carbon fibers with enhanced lithium storage performance. Angew. Chem. Int. Ed. 56(45), 14107-14112 (2017). https://doi.org/10.1002/anie.201708105

19. B. Guo, T. Yang, W. Du, Q. Ma, L.-Z. Zhang et al., Doublewalled N-doped carbon@ $\mathrm{NiCo}_{2} \mathrm{~S}_{4}$ hollow capsules as $\mathrm{SeS}_{2}$ hosts for advanced $\mathrm{Li}-\mathrm{SeS}_{2}$ batteries. J. Mater. Chem. A 7(19), 12276-12282 (2019). https://doi.org/10.1039/c9ta0 $2695 \mathrm{a}$

20. X. Fu, W.H. Zhong, Biomaterials for high-energy lithiumbased batteries: strategies, challenges, and perspectives. Adv. Energy Mater. 9(40), 1901774 (2019). https://doi.org/10.1002/ aenm.201901774

21. Q. Dong, R. Shen, C. Li, R. Gan, X. Ma et al., Construction of soft base tongs on separator to grasp polysulfides from shuttling in lithium-sulfur batteries. Small 14(52), 1804277 (2018). https://doi.org/10.1002/smll.201804277

22. L. Ni, G. Yang, Q. Wang, S. Duan, C. Shen et al., Supramolecular complexation of polysulfides by $\beta$-cyclodextrin polymer functionalized graphene hybrid cathode for high-performance lithium-sulfur batteries. Energy Storage Mater. 21, 378-389 (2019). https://doi.org/10.1016/j.ensm.2018.12.002

23. T. Liu, S. Sun, W. Song, X. Sun, Q. Niu et al., A lightweight and binder-free electrode enabled by lignin fibers@carbonnanotubes and graphene for ultrastable lithium-sulfur batteries. J. Mater. Chem. A 6(46), 23486-23494 (2018). https://doi. org/10.1039/c8ta08521h

24. S. Tu, X. Chen, X. Zhao, M. Cheng, P. Xiong et al., A polysulfide-immobilizing polymer retards the shuttling of polysulfide intermediates in lithium-sulfur batteries. Adv. Mater. 30(45), 1804581 (2018). https://doi.org/10.1002/adma.20180 4581

25. X. Fu, L. Scudiero, W.-H. Zhong, A robust and ion-conductive protein-based binder enabling strong polysulfide anchoring for high-energy lithium-sulfur batteries. J. Mater. Chem. A 7(4), 1835-1848 (2019). https://doi.org/10.1039/c8ta11384j

26. M. Chen, C. Li, X. Fu, W. Wei, X. Fan et al., Let it catch: a short-branched protein for efficiently capturing polysulfides in lithium-sulfur batteries. Adv. Energy Mater. 10(9), 1903642 (2020). https://doi.org/10.1002/aenm.201903642

27. Y. Liu, H.B. Jiang, Z.P. Xu, Y.G. Cheng, S.W. Lv et al., New glycosides from the fruits of nicandra physaloides. Molecules 22(5), 828 (2017). https://doi.org/10.3390/molecules220508 28

28. L.-Q. Wang, Y. Wang, S.-Y. Gao, L.-H. Zhu, F. Wang et al., Phenolic amides with anti-Parkinson's disease (PD) effects from Nicandra physaloides. J. Funct. Foods 31, 229-236 (2017). https://doi.org/10.1016/j.jff.2017.01.045

29. Q. Niu, B. Wang, T. Li, X. Jin, Y. Chen, Structure and gel characterization of petic polysaccharide from nicandra physaloides (L.) gaertn seeds. Mod. Food Sci. Technol. 31(9), 68-73 (2015). https://doi.org/10.13982/j.mfst.16739078.2015.9.012

30. M. Govindarajan, H.F. Khater, C. Panneerselvam, G. Benelli, One-pot fabrication of silver nanocrystals using Nicandra physalodes: a novel route for mosquito vector control with moderate toxicity on non-target water bugs. Res. Vet. Sci. 107, 95-101 (2016). https://doi.org/10.1016/j.rvsc.2016.05.017

31. Z. Wang, Y. Dong, H. Li, Z. Zhao, H.B. Wu et al., Enhancing lithium-sulphur battery performance by strongly binding the discharge products on amino-functionalized reduced graphene oxide. Nat. Commun. 5, 5002 (2014). https://doi.org/10.1038/ ncomms6002

32. H. Jiang, L. Huang, Y. Wei, B. Wang, H. Wu et al., Bio-derived hierarchical multicore-shell $\mathrm{Fe}_{2} \mathrm{~N}$-nanoparticle-impregnated $\mathrm{N}$-doped carbon nanofiber bundles: a host material for lithium-/potassium-ion storage. Nano-Micro Lett. 11(1), 56 (2019). https://doi.org/10.1007/s40820-019-0290-0

33. J. Liu, A. Wei, G. Pan, Q. Xiong, F. Chen et al., Atomic layer deposition-assisted construction of binder-free Ni@N-doped carbon nanospheres films as advanced host for sulfur cathode. 
Nano-Micro Lett. 11(1), 64 (2019). https://doi.org/10.1007/ s40820-019-0295-8

34. X. Lin, K. Liu, S. Yin, Y. Qin, P. Shen et al., A novel pectic polysaccharide of jujube pomace: structural analysis and intracellular antioxidant activities. Antioxidants 9(2), 127 (2020). https://doi.org/10.3390/antiox9020127

35. M. Acik, G. Lee, C. Mattevi, A. Pirkle, R.M. Wallace et al., The role of oxygen during thermal reduction of graphene oxide studied by infrared absorption spectroscopy. J. Phys. Chem. C 115(40), 19761-19781 (2011). https://doi.org/10. 1021/jp2052618

36. G. Li, M. Ling, Y. Ye, Z. Li, J. Guo et al., Acacia senegalinspired bifunctional binder for longevity of lithium-sulfur batteries. Adv. Energy Mater. 5(21), 1500878 (2015). https:// doi.org/10.1002/aenm.201500878

37. F. Huang, H. Liu, R. Zhang, L. Dong, L. Liu et al., Physicochemical properties and prebiotic activities of polysaccharides from longan pulp based on different extraction techniques. Carbohydr. Polym. 206, 344-351 (2019). https://doi.org/10. 1016/j.carbpol.2018.11.012

38. L. Zhang, Y. Hu, X. Duan, T. Tang, Y. Shen et al., Characterization and antioxidant activities of polysaccharides from thirteen boletus mushrooms. Int. J. Biol. Macromol. 113, 1-7 (2018). https://doi.org/10.1016/j.ijbiomac.2018.02.084

39. T.Z. Hou, W.T. Xu, X. Chen, H.J. Peng, J.Q. Huang, Q. Zhang, Lithium bond chemistry in lithium-sulfur batteries. Angew. Chem. Int. Ed. 56(28), 8178-8182 (2017). https://doi.org/10. 1002/anie. 201704324

40. T. Maihom, S. Kaewruang, N. Phattharasupakun, P. Chiochan, J. Limtrakul et al., Lithium bond impact on lithium polysulfide adsorption with functionalized carbon fiber paper interlayers for lithium-sulfur batteries. J. Phys. Chem. C 122(13), 70337040 (2018). https://doi.org/10.1021/acs.jpcc.7b09392

41. H. Cheng, B. Gu, M.P. Pennefather, T.X. Nguyen, N. PhanThien et al., Cotton aerogels and cotton-cellulose aerogels from environmental waste for oil spillage cleanup. Mater. Des. 130, 452-458 (2017). https://doi.org/10.1016/j.matdes.2017. 05.082

42. X. Gao, B. Wang, Y. Zhang, H. Liu, H. Liu et al., Graphenescroll-sheathed $\alpha-\mathrm{MnS}$ coaxial nanocables embedded in $\mathrm{N}, \mathrm{S}$ Co-doped graphene foam as 3D hierarchically ordered electrodes for enhanced lithium storage. Energy Storage Mater. 16, 46-55 (2019). https://doi.org/10.1016/j.ensm.2018.04.027

43. J.P. Song, L. Wu, W.D. Dong, C.F. Li, L.H. Chen et al., MOFderived nitrogen-doped core-shell hierarchical porous carbon confining selenium for advanced lithium-selenium batteries. Nanoscale 11(14), 6970-6981 (2019). https://doi.org/10.1039/ c9nr00924h

44. M. Xiang, H. Wu, H. Liu, J. Huang, Y. Zheng et al., A flexible 3D multifunctional MgO-decorated carbon foam@ CNTs hybrid as self-supported cathode for high-performance lithium-sulfur batteries. Adv. Funct. Mater. 27(37), 1702573 (2017). https://doi.org/10.1002/adfm.201702573

45. M. Shi, S. Zhang, Y. Jiang, Z. Jiang, L. Zhang et al., Sandwiching sulfur into the dents between $\mathrm{N}$, O Co-doped graphene layered blocks with strong physicochemical confinements for stable and high-rate Li-S batteries. Nano-Micro Lett. 12(1), 146 (2020). https://doi.org/10.1007/s40820-020-00477-3

46. Z. Li, H.-Y. Zhou, F.-L. Zhao, T.-X. Wang, X. Ding et al., Three-dimensional covalent organic frameworks as host materials for lithium-sulfur batteries. Chin. J. Polym. Sci. 38(5), 550-557 (2020). https://doi.org/10.1007/s10118-020-2384-Z

47. R. Guan, L. Zhong, S. Wang, D. Han, M. Xiao et al., Synergetic covalent and spatial confinement of sulfur species by phthalazinone-containing covalent triazine frameworks for ultrahigh performance of Li-S batteries. ACS Appl. Mater. Interfaces 12(7), 8296-8305 (2020). https://doi.org/10.1021/ acsami. $9 \mathrm{~b} 21481$

48. G. Li, W. Lei, D. Luo, Y.-P. Deng, D. Wang et al., 3D Porous carbon sheets with multidirectional ion pathways for fast and durable lithium-sulfur batteries. Adv. Energy Mater. 8(8), 1702381 (2018). https://doi.org/10.1002/aenm.201702381

49. X. Liang, C.Y. Kwok, F. Lodi-Marzano, Q. Pang, M. Cuisinier et al., Tuning transition metal oxide-sulfur interactions for long life lithium sulfur batteries: the "goldilocks" principle. Adv. Energy Mater. 6(6), 1501636 (2016). https://doi.org/10. 1002/aenm.201501636

50. Y. Guo, Y. Zhang, Y. Sun, Y. Zhang, H. Wu, Graphene-nanoscroll-based Integrated and self-standing electrode with a sandwich structure for lithium sulfur batteries. Inorg. Chem. Front. 7(3), 592-596 (2020). https://doi.org/10.1039/c9qi0 $1344 \mathrm{j}$

51. Y. Wei, B. Wang, Y. Zhang, M. Zhang, Q. Wang et al., Rational design of multifunctional integrated host configuration with lithiophilicity-sulfiphilicity toward high-performance Li-S full batteries. Adv. Funct. Mater. 31, 2006033 (2021). https://doi.org/10.1002/adfm.202006033

52. H. Wu, Y. Li, J. Ren, D. Rao, Q. Zheng et al., CNT-assembled dodecahedra core@ nickel hydroxide nanosheet shell enabled sulfur cathode for high-performance lithium-sulfur batteries. Nano Energy 55, 82-92 (2019). https://doi.org/10.1016/j. nanoen.2018.10.061

53. G. Li, X. Wang, M.H. Seo, M. Li, L. Ma et al., Chemisorption of polysulfides through redox reactions with organic molecules for lithium-sulfur batteries. Nat. Commun. 9(1), 705 (2018). https://doi.org/10.1038/s41467-018-03116-z

54. L. Jin, G. Li, B. Liu, Z. Li, J. Zheng et al., A novel strategy for high-stability lithium sulfur batteries by in situ formation of polysulfide adsorptive-blocking layer. J. Power Sources 355, 147-153 (2017). https://doi.org/10.1016/j.jpowsour.2017.04. 059

55. Q. Pang, D. Kundu, M. Cuisinier, L.F. Nazar, Surfaceenhanced redox chemistry of polysulphides on a metallic and polar host for lithium-sulphur batteries. Nat. Commun. 5, 4759 (2014). https://doi.org/10.1038/ncomms5759

56. K. Han, Z. Liu, J. Shen, Y. Lin, F. Dai et al., A free-standing and ultralong-life lithium-selenium battery cathode enabled by 3D mesoporous carbon/graphene hierarchical architecture. Adv. Funct. Mater. 25(3), 455-463 (2015). https://doi.org/10. 1002/adfm.201402815

57. S.-K. Park, J.-S. Park, Y.C. Kang, Selenium-infiltrated metal-organic framework-derived porous carbon nanofibers 
comprising interconnected bimodal pores for $\mathrm{Li}-\mathrm{Se}$ batteries with high capacity and rate performance. J. Mater. Chem. A 6(3), 1028-1036 (2018). https://doi.org/10.1039/c7ta09676c

58. X. Wang, Y. Tan, Z. Liu, Y. Fan, M. Li et al., New insight into the confinement effect of microporous carbon in Li/Se battery chemistry: a cathode with enhanced conductivity. Small (2020). https://doi.org/10.1002/smll.202000266

59. Y. Yao, H. Wang, H. Yang, S. Zeng, R. Xu et al., A dualfunctional conductive framework embedded with TiN-VN heterostructures for highly efficient polysulfide and lithium regulation toward stable Li-S full batteries. Adv. Mater. 32(6), 1905658 (2020). https://doi.org/10.1002/adma.201905658

60. Y. Boyjoo, H. Shi, E. Olsson, Q. Cai, Z.S. Wu et al., Molecular-level design of pyrrhotite electrocatalyst decorated hierarchical porous carbon spheres as nanoreactors for lithiumsulfur batteries. Adv. Energy Mater. 10(20), 2000651 (2020). https://doi.org/10.1002/aenm.202000651

61. G. Zhou, A. Yang, G. Gao, X. Yu, J. Xu et al., Supercooled liquid sulfur maintained in three-dimensional current collector for high-performance Li-S batteries. Sci. Adv. 6(21), eaay5098 (2020). https://doi.org/10.1126/sciadv.aay5098

62. D. Tian, X. Song, M. Wang, X. Wu, Y. Qiu et al., MoN supported on graphene as a bifunctional interlayer for advanced Li-S batteries. Adv. Energy Mater. 9(46), 1901940 (2019). https://doi.org/10.1002/aenm.201901940

63. H. Yuan, H.-J. Peng, B.-Q. Li, J. Xie, L. Kong et al., Conductive and catalytic triple-phase interfaces enabling uniform nucleation in high-rate lithium-sulfur batteries. Adv. Energy Mater. 9(1), 1802768 (2019). https://doi.org/10.1002/aenm. 201802768

64. Y. Zhao, W. Cai, Y. Fang, H. Ao, Y. Zhu et al., Sulfur-deficient $\mathrm{TiS}_{2-\mathrm{x}}$ for promoted polysulfide redox conversion in lithiumsulfur batteries. ChemElectroChem 6(8), 2231-2237 (2019). https://doi.org/10.1002/celc.201900269

65. P. Jing, Q. Wang, B. Wang, X. Gao, Y. Zhang et al., Encapsulating yolk-shell $\mathrm{FeS}_{2} @$ carbon microboxes into interconnected graphene framework for ultrafast lithium/sodium storage. Carbon 159, 366-377 (2020). https://doi.org/10.1016/j. carbon.2019.12.060

66. Y. Wang, P. Liang, H. Yang, W. Li, Z. Wang et al., Hollow CoP nanoparticles embedded in two-dimensional $\mathrm{N}$-doped carbon arrays enabling advanced $\mathrm{Li}-\mathrm{SeS}_{2}$ batteries with rapid kinetics. Mater. Today Energy 17, 100423 (2020). https://doi.org/ 10.1016/j.mtener.2020.100423

67. Z. Shi, Z. Sun, J. Cai, Z. Fan, J. Jin et al., Boosting dual-directional polysulfide electrocatalysis via bimetallic alloying for printable Li-S batteries. Adv. Funct. Mater. 31(4), 2006798 (2020). https://doi.org/10.1002/adfm.202006798

68. H. Li, Y. Wang, H. Chen, B. Niu, W. Zhang et al., Synergistic mediation of polysulfide immobilization and conversion by a catalytic and dual-adsorptive system for high performance lithium-sulfur batteries. Chem. Eng. J. 406, 126802 (2021). https://doi.org/10.1016/j.cej.2020.126802

69. X. Chen, T. Hou, K.A. Persson, Q. Zhang, Combining theory and experiment in lithium-sulfur batteries: current progress and future perspectives. Mater. Today 22, 142-158 (2019). https://doi.org/10.1016/j.mattod.2018.04.007

70. T. Yang, Y. Qi, W. Zhong, M. Tao, B. Guo et al., A strategy for polysulfides/polyselenides protection based on $\mathrm{Co}_{9} \mathrm{~S}_{8} @ \mathrm{SiO}_{2} / \mathrm{C}$ host in $\mathrm{Na}-\mathrm{SeS}_{2}$ batteries. Adv. Funct. Mater. 31(2), 2001952 (2020). https://doi.org/10.1002/adfm.202001952

71. A. Goldbach, L. Iton, M. Grimsditch, M.-L. Saboungi, The formation of $\mathrm{Se}_{2}^{-}$: A new resonance raman feature in the photochemistry of zeolite-encapsulated selenium. J. Am. Chem. Soc. 118, 2004-2007 (1996). https://doi.org/10.1021/ja953 1788

72. C.-P. Yang, S. Xin, Y.-X. Yin, H. Ye, J. Zhang et al., An advanced selenium-carbon cathode for rechargeable lithiumselenium batteries. Angew. Chem. Int. Ed. 52, 8363-8367 (2013). https://doi.org/10.1002/anie.201303147

73. Y. Hao, D. Xiong, W. Liu, L. Fan, D. Li et al., Controllably designed "vice-electrode" interlayers harvesting high performance lithium sulfur batteries. ACS Appl. Mater. Interfaces 9(46), 40273-40280 (2017). https://doi.org/10.1021/acsami. $7 \mathrm{~b} 12710$

74. C. Yan, X.-B. Cheng, C.-Z. Zhao, J.-Q. Huang, S.-T. Yang et al., Lithium metal protection through in-situ formed solid electrolyte interphase in lithium-sulfur batteries: The role of polysulfides on lithium anode. J. Power Sources 327, 212-220 (2016). https://doi.org/10.1016/j.jpowsour.2016.07.056

75. L. Zhang, M. Ling, J. Feng, L. Mai, G. Liu et al., The synergetic interaction between $\mathrm{LiNO}_{3}$ and lithium polysulfides for suppressing shuttle effect of lithium-sulfur batteries. Energy Storage Mater. 11, 24-29 (2018). https://doi.org/10.1016/j. ensm.2017.09.001

76. J.Y. Wei, X.Q. Zhang, L.P. Hou, P. Shi, B.Q. Li et al., Shielding polysulfide intermediates by an organosulfur-containing solid electrolyte interphase on the lithium anode in lithiumsulfur batteries. Adv. Mater. 32(37), 2003012 (2020). https:// doi.org/10.1002/adma.202003012

77. Y. Song, Z. Sun, Z. Fan, W. Cai, Y. Shao et al., Rational design of porous nitrogen-doped $\mathrm{Ti}_{3} \mathrm{C}_{2}$ MXene as a multifunctional electrocatalyst for Li-S chemistry. Nano Energy 70, 104555 (2020). https://doi.org/10.1016/j.nanoen.2020.104555

78. J. Liu, Z. Li, B. Jia, J. Zhu, W. Zhu et al., A freestanding hierarchically structured cathode enables high sulfur loading and energy density of flexible Li-S batteries. J. Mater. Chem. A 8(13), 6303-6310 (2020). https://doi.org/10.1039/c9ta14240a 